\title{
Universiteit
}

Leiden

The Netherlands

\section{Long-RNA sequencing and ribosome profiling of inflamed beta-cells reveal an extensive translatome landscape}

Thomaidou, S.; Slieker, R.C.; Slik, A.R. van der; Boom, J.; Mulder, F.; Munoz-Garcia, A.; ... ; Zaldumbide, A.

\section{Citation}

Thomaidou, S., Slieker, R. C., Slik, A. R. van der, Boom, J., Mulder, F., Munoz-Garcia, A., ... Zaldumbide, A. (2021). Long-RNA sequencing and ribosome profiling of inflamed beta-cells reveal an extensive translatome landscape. Diabetes. doi:doi.org/10.2337/db20-1122

Version: $\quad$ Not Applicable (or Unknown)

License: $\quad$ Leiden University Non-exclusive license

Downloaded from: https://hdl.handle.net/1887/3217882

Note: To cite this publication please use the final published version (if applicable). 


\section{Long-RNA sequencing and ribosome profiling of inflamed beta-cells reveal an extensive translatome landscape}

Sofia Thomaidou ${ }^{1}$, Roderick C. Slieker ${ }^{1,2}$, Arno R. van der Slik ${ }^{1,3}$, Jasper Boom ${ }^{4}$, Flip Mulder ${ }^{5}$, Amadeo Munoz-Garcia ${ }^{6}$, Leen M. 't Hart ${ }^{1}$, Bobby Koeleman ${ }^{5}$, Francoise Carlotti ${ }^{6}$, Rob C. Hoeben ${ }^{1}$, Bart O. Roep ${ }^{6,7}$, Hailiang $\mathrm{Mei}^{4}$, Arnaud Zaldumbide ${ }^{1, \#}$

${ }^{1}$ Department of Cell and Chemical Biology, Leiden University Medical Center, Leiden, The Netherlands, ${ }^{2}$ Department of Epidemiology and Biostatistics, Amsterdam Public Health Institute, Amsterdam UMC, location VUMC, Amsterdam, The Netherlands, ${ }^{3}$ Department of Immunohematology and Blood Transfusion, Leiden University Medical Center, ${ }^{4}$ Sequencing Analysis Support Core, Department of Biomedical Data Sciences, Leiden University Medical Center, The Netherlands, ${ }^{5}$ Center for Molecular Medicine, Utrecht Medical Center, Utrecht, The Netherlands, ${ }^{6}$ Department of Internal Medicine, Leiden University Medical Center, The Netherlands, ${ }^{7}$ Department of Diabetes Immunology, Diabetes \& Metabolism Research Institute, City of Hope, Duarte, USA.

\# Corresponding author:

Arnaud Zaldumbide, $\mathrm{PhD}$

Department of Cell and Chemical Biology - Leiden University Medical Center mail stop S1-P, P.O. Box 9600, 2300 RC Leiden, The Netherlands phone: +31 (0) 715269239 ; E-mail: a.zaldumbide@lumc.nl

Keywords: Type 1 diabetes; inflammation; alternative splicing; alternative reading frames; autoantigens 


\begin{abstract}
Type 1 diabetes is an autoimmune disease characterized by autoreactive $\mathrm{T}$-cell mediated destruction of the insulin-producing pancreatic beta-cells. Increasing evidence suggest that the beta-cells themselves contribute to their own destruction by generating neo-antigens through the production of aberrant or modified proteins that escape central tolerance. We have recently demonstrated that ribosomal infidelity amplified by stress could lead to the generation of neoantigens in human beta-cells, emphasizing the participation of nonconventional translation events to autoimmunity, as occurring in cancer or virus-infected tissues. Using a transcriptomewide profiling approach to map translation initiation start sites in human beta-cells under standard and inflammatory conditions, we identify a completely new set of polypeptides derived from noncanonical start sites and translation initiation within lncRNA. Our data underline the extreme diversity of the beta-cell translatome and may reveal new functional biomarkers for beta-cell distress, disease prediction and progression and therapeutic intervention in type 1 diabetes.
\end{abstract}




\section{INTRODUCTION}

Type 1 diabetes (T1D) is an autoimmune disease characterized by the selective and progressive destruction of the insulin-producing pancreatic beta-cells by the invading immune cells(1-3) . Tcells of high affinity are normally eliminated in the thymus by negative selection in order to establish central tolerance. In autoimmune disease, impaired thymic education or low affinity Tcells are believed to be responsible for the immune attack directed against native self-proteins(4). Yet, there is increasing evidence that local inflammation or other forms of stress combined with genetic predisposition leads to the generation and accumulation of aberrant or modified proteins to which central tolerance is lacking and increased visibility of beta-cells to immune cells (5-7). Metabolic and inflammatory stress may perturb the cellular equilibrium and affect high fidelity transcriptional and translational processes during conversion of the genetic information into proteins. We and others have shown increased RNA splicing in beta-cells when maintained under pathophysiological conditions $(8 ; 9)$, as well as T-cell autoreactivity against deamidated autoantigens and fusion epitopes illustrating that transcriptional, post-transcriptional and posttranslational processes can be affected during insulitis, supporting the participation of unconventional antigens in T1D pathology(10-13). While transcription regulation is a slow process, translation and ribosome position along RNA molecules can change upon stress in a matter of seconds (14). Many genes involved in the unfolded protein response to stress are regulated at a translational level. This swift cell adaptation is illustrated by the regulation of stress responsive genes (i.e. $A T F 4, A T F 5, G A D D 34$ or $C H O P$ ), where the activation of the PERK sensor within the ER triggers phosphorylation of the translation initiation factor eIF2 and the translational activation of ATF4 controlling the unfolded protein response(15). In this classical model of translation initiation, the RNA precursor is converted into mature RNA by addition of 7- 
methylguanosine $(\mathrm{m} 7 \mathrm{G})$ at its $5^{\prime}$; addition of a poly A tail in 3 ' end; and splicing of intronic regions. Canonically, 5' capping of the mRNA and binding of the 40s ribosomal subunit via the eIF4 factor represents the earliest stage of translation initiation from which mRNA scanning process continues until recognition of a start codon where the complete 80 s ribosome complex starts translation upon recognition of an AUG by the first methionine charged initiator tRNA. Based on this model, the identification of proteins expressed by a cell can be predicted from transcriptomics data analysis. However, the translation process is not flawless and non-canonical initiation can occur(16). In addition, environmental perturbation may affect translation fidelity and cellular stress aggravates translation initiation at alternative start codons with possible consequences at the immunological level(17). In fact, changes in reading frame will necessarily affect the amino acid sequence encoded by RNA molecules. Being recognized as danger signal or just as a translational error, these so-called 'alternative open reading frames products may trigger cell destruction by the immune surveillance. These non-conventional translational events arising from translation of normally untranslated regions (UTR), ribosomal frame-shifting or alternative translation initiation (uTIS or dTIS), represent a unique pool of antigenic peptides that rapidly undergo degradation to the proteasome $(18 ; 19)$. Such epitopes have been described frequently in tumor cells (i.e. ARFs, MELOE, NY-ESO-1, and LAGE-1), and are currently explored as tumor biomarkers or as therapeutic targets to promote a specific anti-tumor response(13). Surprisingly, in the context of autoimmunity, these neoepitopes have rarely been investigated(20), in spite of reports estimating that up to $70 \%$ of peptides presented at the cell surface in MHC class I may be derived from defective ribosomal products(21). We have recently shown that translation of the human insulin mRNA can generate translational errors that participate to beta-cell destruction providing the first evidence for the implication of translational "junk" products in triggering 
autoimmunity(22). However, current transcriptomic, proteomic and peptidomic approaches aiming at extending our view on the beta-cell ligandome and improving our understanding on potential involvement of beta-cell to T1D pathogenesis(23) are not compatible with the detection of out-of-frame rapidly degraded polypeptide products, thereby masking important features of the beta-cell ligandome.

We used a novel unbiased proteogenomic approach to identify all possible open reading frames (ORFs) generated by beta-cells maintained in normal and T1D pathophysiological conditions. Our results uncover evidence for translation initiation in novel RNA transcripts as well as long noncoding RNA. Moreover, we show that cytokine treatment leads to profound changes in genes involved in MHC-class I processing and a significantly increased number of ORFs per transcript and in particular an increased ribosome density within 5'-UTR regions. Altogether, our data present new insights in the dynamic regulation of transcription and translation revealing an extended beta-cell translatome. 


\section{RESEARCH DESIGN AND METHODS}

\section{Cells and reagents.}

EndoC- $\beta \mathrm{H} 1$ cells, kindly provided by Dr. Raphael Scharfmann (Paris Descartes University, France)(24), were maintained in low glucose DMEM supplemented with $5.5 \mu \mathrm{g} / \mathrm{ml}$ human transferrin, $10 \mathrm{mM}$ Nicotinamide, $6.7 \mathrm{ng} / \mathrm{ml}$ Selenit, $50 \mu \mathrm{M} \beta$-mercaptoethanol, $2 \%$ human albumin, 100 units $/ \mathrm{ml}$ Penicillin and $100 \mu \mathrm{g} / \mathrm{ml}$ streptomycin. Cells were seeded in ECM, fibronectin pre-coated culture plates. Inflammatory stress was induced by a mixture of $1000 \mathrm{U} / \mathrm{ml}$ IFN $\gamma$ and $2 \mathrm{ng} / \mathrm{ml} \mathrm{IL1} \beta$ for $24 \mathrm{~h}$. Upon incubation, cells were treated with $2 \mathrm{ug} / \mathrm{ml}$ harringtonine for 30 minutes at $37^{\circ} \mathrm{C}$, as previously described(16). Cycloheximide (100ug/ml) was added for 30 seconds. Ten million cells were used per condition. Subsequent cell lysis was performed without freezing as described using $900 \mathrm{ul}$ of lysis buffer. The clarified lysates were stored overnight at $80{ }^{\circ} \mathrm{C}$.

\section{Nuclease footprinting and ribosome recovery.}

The materials and methods used are adapted from previously described protocol(25). Following cell lysis (20mM Tris $\mathrm{Cl}(\mathrm{Ph} 7.4), 150 \mathrm{mM} \mathrm{NaCl}, 5 \mathrm{mM} \mathrm{MgCl} 2$, 1mM DTT supplemented with 100ug/ml cycloheximide, $1 \%$ Triton X-100 and 25U/ml Turbo DNaseI), ribosome complexes were purified by adding three times the volume of sucrose cushion to the clarified lysate solution in Thickwall Polycarbonate Tube, 13x64mm (Beckman Coulter Life Sciences, part no. 344645). Ribosomes were pelleted by centrifugation using Delrin Tube Adapters (Beckman Coulter Life Sciences, part no. 303313) in a Type 70.1 Ti Fixed-Angle Titanium Rotor (Beckman Coulter Life Sciences, part no. 337922). The ribosomal pellets were further lysed using $300 \mu 1$ Buffer ML from the Nucleospin miRNA Kit (Bioke, product code 740971). Lysates were stored overnight at -80 
${ }^{\circ} \mathrm{C}$ and RNA purified using Nucleospin miRNA according to the manufacturer's guidelines. The RNA was precipitated using Glycogen, RNA grade (Thermofisher Scientific, cat. no. R0551) and resuspended in $10 \mu 1$ of DEPC-Treated Water (ThermoFisher Scientific, cat. no. AM9920).

\section{Footprint fragment purification.}

Purified RNA was denaturated (98\%(vol/vol) formamide, 10mM EDTA. 300ug/ml bromophenol blue) and load on $18 \%$ (wt/vol) polyacrylamide TBE-urea gel (200 V for 90 min in 1x TBE buffer). Molecular weight ladder a mix was prepared of $5 \mu 1$ microRNA Marker (New England Biolabs, cat. no. N2102), and $0.5 \mu 1$ Small RNA Marker (Abnova, cat. no. R0007). The SYBR Gold (ThermoFisher Scientific, cat. no. S11494) stained gel was visualised using a ChemiDoc MP Imaging System (Bio-Rad). RNA was extracted from excised gel slices spanning the $26 \mathrm{nt}$ to 34 nt region, using the ZR small-RNA PAGE Recovery Kit (Zymo Research, cat. no. R1070) according to the manufacturer's protocol. The size-selected RNA was stored at $-80^{\circ} \mathrm{C}$.

\section{Dephosphorylation and linker ligation.}

Dephosphorylation reaction and linker ligation were performed using the Universal miRNA Cloning linker (New England Biolabs, cat. no. S1315S) in a T100 Thermal Cycler (Bio-Rad, product number 1861096). RNA was precipitated using Glycogen, RNA grade (Thermofisher Scientific, cat. no. R0551) and resuspended in $10 \mu 1$ of DEPC-treated Water (ThermoFisher Scientific, cat. no. AM9920). Size separation and gel extraction of the ligation reaction were performed as described in the footprint fragment purification section.

\section{Reverse transcription and circularization.}


The reverse transcription reaction was performed in a T100 Thermal Cycler using RT primers). Gel extraction were performed as described in the footprint fragment purification section and cDNA circularized using CircLigase following guidelines from the manufacturer.

\section{Ribosomal RNA depletion and barcoding.}

The rRNA depletion was performed using a T100 thermal cycler (Bio-Rad) and a Thermomixer 5350 Mixer (Eppendorf) using depletion primers (Table 1). PCR was performed using library preparation primers. PCR strips were removed at the end of the extension step after 7, 8, 9, 10, 11, and 12 cycles. The samples were separated by electrophoresis using a $9 \%(\mathrm{wt} / \mathrm{vol})$ polyacrylamide TBE-urea gel at $180 \mathrm{~V}$ for $45 \mathrm{~min}$ in $1 \mathrm{x}$ TBE. As molecular weight marker $5 \mu 150 \mathrm{bp}$ DNA Ladder (New England Biolabs, cat. no. B7025) was included. The SYBR gold stained gel was visualized using a ChemiDoc MP (Biorad). Excised gel slices containing the amplicons were crushed and soaked overnight at room temperature under gentle mixing, using $400 \mu \mathrm{l}$ diffusion buffer for PAGE gels (500 mM ammonium, pH 8.0, 0.1\% SDS, $1 \mathrm{mM}$ EDTA, $10 \mathrm{mM}$ magnesium acetate) and Nucleospin Gel \& PCR Clean-up (Bioke, product code 740609). Subsequently, the libraries were isolated from the extraction mix according to the manufacturer's recommendations and eluted in $30 \mu 1$ Elution Buffer NE. The libraries were quantified and characterized using the Experion DNA 1K Analysis Kit (Bio-Rad, product number 7007107) on a Experion Automated Electrophoresis System (Bio-Rad) following the manufacturer's protocol. 


\section{RESULTS}

\section{Precise mapping of the translation initiation start sites in beta-cells by ribosome profiling.}

To evaluate translational changes induced by proinflammatory cytokines during the early events of type 1 diabetes, we treated the human beta-cell line EndoC- $\beta \mathrm{H} 1$ with proinflammatory cytokines (IFN $\gamma$ and IL1 $\beta$ ) and isolated ribosome protected fragments to map translation initiation sites (TIS) ( $\mathrm{n}=3$ independent experiments). Using a combined treatment with harringtonine that incorporates at the A-site of the large 60S ribosomal subunit, thereby blocking the entry of a second tRNA, and cycloheximide that displays a high affinity for the uncharged tRNA E-pocket of the $80 \mathrm{~S}$ complex thereby preventing further elongation, we froze ribosomes at the initiation of translation(16; 25; 26). Following RNAseI treatment, polysomes were purified and ribosomes protected fragments (RPFs) isolated to generate ribosome footprint libraries containing the translation initiation sites(25) (Fig.1A). As anticipated from the stoichiometric hindrance of ribosomes on RNA molecules, the length of fragments sequenced ranged from 26 to 31 nucleotides independently of the treatment (Fig.1B). Alignment of the RPFs to the human transcriptome revealed an accumulation of reads at the beginning of the translated region of the transcripts, consequence of the high ribosome occupancy at the translation start (Fig.S1A). For reads of same length, P-site offsets were computed to precisely map the position of the ribosome P-site, corresponding to the start codon, on the RNA footprint(27). Shorter incubation with harringtonine failed to stop the ribosome complex at the start codon leading to noise during elongation and accumulation of reads at 3' UTR resulting from ribosome stalling before completing peptide synthesis (Fig.S1B). The occupancy profiles of the RPFs 5' and 3' end extremities around the referenced start codons, showed accumulation of read ends at locations +/- 12 (Fig.S1C), validating both ribosomal freezing and computational calculation allowing mapping of the start 
site (Fig.S1D-E). In order to eliminate false-positives and minimize background artifacts resulting from the speed of transcript translation, incomplete blockade by translation inhibitors or possible non-ribosomal protein complexes interacting with the mRNA, we developed an algorithm based on the read distribution surrounding the suspected P-site to identify the most relevant translation initiation starts. Reasoning that the accumulation of RPFs at a start position are normally distributed, the read spread in flanking position is determined by the number of reads of the peak, we defined an enrichment method using a dynamic sliding window encompassing each P-site site position (Supplementary materials and Fig.S2A-B). Significance testing was performed using a negative binomial regression model, and samples belonging to different library preparations and treatment were statistically paired. Using this enrichment method, we identified 15014 start sites within 5529 genes in both untreated and cytokine treated samples (Fig.1C and data file S1). Codon occupancy analysis at the E, P and A pockets indicated a conserved AUG motif at the Psite within a Kozak consensus sequence both in non-treated and cytokine- treated samples (Fig.1D).

\section{Direct RNA sequencing and Ribo-seq technology reveals active translation in novel transcript variants and long non-coding RNA.}

In order to evaluate the impact of cytokine stimulation on translation, we performed a negative binomial regression on the read numbers at the P-site position. As expected, pathways related to inflammatory response, such as antigen processing, presentation and apoptosis, were induced upon treatment (Fig.2A). More specifically, translation initiation within transcripts of these inflammatory pathways was significantly upregulated (p-value $<0.05$ and $\log _{2}$ Fold Change $>1.5$ )

(Fig.2B). Increased expression of key proteins for secretory pathway (CHGA), IFN signaling 
(STAT1, STAT2) and antigen processing (PSMB8, PSMB9 and PSMB10) was validated by western blot in EndoC- $\beta \mathrm{H} 1$ cells and confirmed in primary human islets (Supplementary Fig. S3). While these data do not provide proofs for expression of the alternative ORFs, they contribute to technical validation of the ribosome profiling approach. Despite a stringent detection method, $17 \%$ of P-sites identified corresponded to referenced annotated start codon (Fig.2C). Importantly, we identified several misannotated translational start sites (i.e. TAP1 and PSMD8) experimentally validated in previous ribosome profiling assays (TISdb database)(28) or extra start sites previously confirmed by mass spectrometry (i.e. YBX1 and PGRMC1) (Fig.S4A-D). By reconstituting the 3 base periodicity move of the ribosomes on RNA molecule from the identified start sites, our analysis revealed a wide range of novel or modified ORFs leading to translation rearrangements (upstream initiation: uORF that ends before the coding sequence (CDS), N-terminal extension of annotated protein, overlapping uORF spanning 5'-UTRs and CDS on an alternative frame/ translation frameshift: internal off-frame, downstream initiation: initiation on the 3'-UTR) (Fig.2D). Moreover, we detected a considerable fraction (7\%) of the RPFs mapped to non-coding RNA and preferentially in long non-coding RNA (Fig.2E-F). The polypeptide lengths of ORFs initiated at alternative start sites in coding ( $n=25466$ in non-treated and $n=25984$ in cytokine condition) or non-coding RNA ( $\mathrm{n}=2634$ in non-treated and $n=2381$ in cytokine) were smaller than canonical ORFs (Fig.2G). These differences in peptide sizes observed are in line with previous studies conducted on embryonic stem cells and cancer cell lines $(29 ; 30)$.

Moreover, nearly $20 \%$ of the purified ribosome footprints did not align to the referenced transcriptome indicating the presence of TIS on novel transcripts (Fig.3A and data file S2). In order to further explore the beta-cell transcriptome and translatome, we stimulated EndoC- $\beta \mathrm{H} 1$ cells with cytokines and performed direct long RNA sequencing in search for novel transcript 
variants (Supplementary materials and Fig.3B). Following a differential expression analysis, we identified a classical transcriptional inflammatory signature on T1D susceptible genes $(31 ; 32)$ (Fig.3C and data file S3). Long RNA sequencing identified 6892 new transcripts, among which 37 were specifically present under inflammatory condition (Fig.3D). In order to validate our results, we aligned reads from our denovo transcriptome to RNA sequencing datasets from pancreatic $\beta$ cells (33). As described in Supplementary Figure S5A-B and data file S4, 74\% of the newly identified transcripts spanning over splicing junctions in beta cell line (77\% of the T1D susceptible genes) are supported by RNA-seq reads from primary beta cell enriched fraction. In addition, we evaluated the expression pattern of 2 novel cytokines specific transcripts (i.e. PSMB9 TALONT000709680 and HLA-C TALONT000700063) in EndoCBH1 and primary human islets. As shown in Figure S5, classical RT-PCR analysis confirmed the cytokine specificity in EndoC$\beta \mathrm{H} 1$, the expression in islets may illustrate the difference between EndoC- $\beta \mathrm{H} 1$ and primary beta cell but more likely reflect the presence of other islet cell types in the RNA preparation) (Fig. S5CF).

Alignment of the RPFs to the newly defined beta-cell transcriptome revealed over 1745 TIS located on the novel transcripts, including 499 TIS specifically detected upon treatment (Fig.3E). Importantly, these TIS were surrounded by Kozak-like sequences and could potentially give rise to ORFs 150aa long (Fig.3F-G and data file S5). By integrating transcriptome and translatome datasets, we evaluated the transcriptional and translational adaptive response to inflammatory cytokines in beta-cells. CST3, PRPS1 and MRPS31 in particular appear regulated at the translational level rather than transcriptional level (Fig.3H and data file S6). 


\section{Cytokine treatment distorts translation fidelity triggering generation of alternative translation initiation sites.}

Metagene distribution of the TIS throughout the whole transcriptome, indicated that cytokine stimulation led to a significant decrease in the number of transcripts presenting a unique start site (P-value $<0.0001)$, and an increased proportion of transcripts with multiple TIS (P-value<0.0001) suggesting that inflammation may actively trigger the generation of intra-transcript initiation events (Fig.4A). Moreover, we observed an increased number of P-sites within 5'-UTR regions ( 4\% increase P-value $<0.0001)$ in cytokine condition when compared to non-treated samples which is in line with studies showing a slower progression of the ribosome complex on RNA during stress condition(34; 35) (Fig.4B). These changes were associated with a modification of the initiation start codon motif (CUG) (Fig.4C). Differential read expression at the alternative TIS showed increased translation efficiency within transcripts involved in the inflammation response, in particular in the 5'UTR and CDS region of HLA, TAP1, TAP2, IFIH1 (Fig.4D). A similar inflammatory response was obtained within newly identified HLA-A and HLA-E transcripts and within transcripts encoding for immunoproteasome subunits (e.g. PSMB9) (Fig.S6A). Within noncoding RNA a higher translation initiation was also detected in non-coding isoforms of PSMB9 and ARF4 transcripts (Fig.S6B). A differential ribosomal occupancy was found specifically in long-non coding RNA in particular within EBLN3P, AL627171.4 or AC112487.1 suggesting an increased production of those small ORF during inflammation (data file S7).

Combining information on translation efficiency at different start sites, we observed a poor correlation between differential read expression at the alternative P-site location and changes at their canonical counterparts $(\mathrm{R}=0.32)$, suggesting specific regulatory mechanisms for translation initiation at each position. Cytokine treatment prevented or favored ribosome docking to 
alternative positions ( $\mathrm{n}=189$ and $\mathrm{n}=135$, respectively) (Fig.4E and data file S8). Pathway analysis performed on these transcripts pointed to an active regulatory mechanism driven by inflammatory signals to adjust RNA splicing and translation machinery in response to stress (Fig.S7). Alternative translation initiation within MAGED2, VEGFA and CHGA transcripts was induced by cytokine stimulation. While no polypeptide could be expected from MAGED2 alternative start (AATstartTGA $\underline{\underline{s t o p}}$ ), we observed an increased ribosome density during inflammation at alternative position within the 5'-UTR and 3'-UTR region of the CHGA transcript that could generate short polypeptides. Using a GFP fusion construct, in which the GFP ORF is positioned in frame with the CGG-103; CCG-40 and CTG-22 start codons identified by ribosome profiling, we validated that the 5'-UTR region can be used to initiate protein translation in a +2 frame (Fig.S8). Of note, translation initiation within 3'-UTR at +1512 could generate a potentially immunogenic polypeptide carrying a strong HLA-A2 epitope. Similarly, within VEGFA transcripts, a novel upstream TIS was identified located upstream the canonical CUG (VEGFA-111), upregulated upon treatment, that can potentially generate two strong HLA-A2 binders (KVSDLLLGV and LLLGVTAGA) (Fig.4E-F). Of note, we detected an extra in frame start site, in position +3 (data not shown), in addition to the canonical CUG start codon (position 0) that carries the SRFGGAVVR epitope, $\sim 7$-fold upregulated upon cytokine treatment, which could drive increased presentation of previously identified cryptic VEGFA epitope(36).

Regarding insulin gene products, a high ribosome density was detected at the canonical start site at position 0 , as expected. Also, extra alternative starts were detected within the 5 '-UTR region at position -44; -34 generating overlapping ORFs (upstream ORF in +1 and +2 reading frame respectively) (Fig.5A and data file S9). Moreover, we detected an accumulation of ribosomes downstream the canonical start site at position 286, confirming that this AUG may serve as docking 
site for translation initiation of the immunogenic out of frame INS-DRiP polypeptide we described earlier(22). Using long RNA sequencing, 5 novel INS transcripts were identified resulting from size variations within exon 1 and 3, intron 1 retention, or 3' extension. While TALONT000499163, TALONT000499165, TALONT000499178 and TALONT000499193 were in low abundance, the INS-IGF2 transcript (TALONT000499153), deriving from the fusion between exon 3 of the INS gene and the INS-IGF2 intronic region is the third most abundant INS transcript expressed by beta cells, representing $3 \%$ of the total INS reads. Using a primer set spanning the end of the classical INS transcript, located in INS exon 3 and in the INS-IGF2 intergenic region, we validated the presence of the TALONT000499153 transcript in EndoC- $\beta$ H1 cells and primary islets and validated the similar transcript abundance, measured by longRNA sequencing, in normal and cytokine condition (Fig.5B). Ribosome density on this region identified a potent translation initiation site that would lead to the generation of a 116 amino acid polypeptide carrying the insulin DRIP epitope and bearing another potential HLA-A2 binder (Fig.5C). To validate alternative translation initiation within INS transcripts in EndoC- $\beta$ H1 cells, we tested the MLYQHLLPL epitope presentation to DRiP specific CD8 T-cell clone. Using JY cells pulsed with insulin derived peptides (PPI: ALWGPDPAAA; B-chain: HLVEALYLV ; DRiP: MLYQHLLPL), we confirmed DRiP T-cell specificity by detecting T cell activation only in presence of the cognate peptide (Fig. 5D). Following genetic modification to express HLA-A2 in EndoCBH1 cells, we validated that the exogenous HLA-A2 expression in presence or absence of cytokines was similar to the endogenous HLA class I expression (Fig. 5E). After co-culture with the DRiP specific CD8 T cells, we detected an increase CD8 activation, measured by CD107a staining and MIP1 $\beta$ release in presence of cytokine stimulation (Fig. 5F) confirming the importance of an HLA 
hyperexpression in beta cell destruction process but also providing proof for processing and presentation of the N-term fragment of the INS alternative ORF in EndoC- $\beta \mathrm{H} 1$ cells. 


\section{DISCUSSION}

The Defective Ribosomal Protein (DRIP) theory arose in 1996(21) when discrepancies between the ligandome and proteome were found in virally infected cells, as a plausible explanation for $\mathrm{T}$ cell reactivity against flu derived peptides detected prior synthesis of their source proteins. Originally identified as prematurely terminated polypeptides and misfolded polypeptides produced from translation of bona-fide mRNAs in the proper reading frame(21), DRiPs include all alternative translation initiation products, including UTR translation and ribosomal frame-shifts products, each of these being susceptible to generate a new pool of antigenic peptides that would not share any, or little, amino acid similarities with genuine mRNA translation products. Such DRIPs are widely studied in viral infections and cancer and are considered as the main target of effective immunosurveillance. In human pancreatic islets, we previously showed that cryptic translation initiation sites can be used during translation of insulin mRNA to generate highly immunogenic insulin-gene derived polypeptide targeted by T-cell autoreactivity in T1D patients, providing proof of principle for the participation of translational errors in autoimmune disease(22). Here, our data reinforce our findings and confirm that DRiPs can be generated from human insulin mRNA, even though no significant effect of cytokines could be detected on this particular start site. The specific killing observed in inflammatory milieu despite similar amounts of DRiP polypeptide in cytokine-treated and untreated beta-cells, illustrates the importance of protein stability, degradation and presentation in beta cell destruction(37). Moreover, combining long RNA sequencing and ribosome profiling, we propose another possible explanation to the origin of this immunogenic polypeptide, through the presence of a novel INS-IGF2 transcript that could serve as template for protein synthesis. In line with these findings, the INS-IGF2 locus has been correlated with autoimmunity and loss of beta-cell functionality in $\operatorname{T1D}(38 ; 39)$. Therefore, 
deciphering its transcriptional and translational profiling in human islets may be crucial for a better understanding of disease onset and progression.

The large dataset of alternative translatome revealed in this study begs for revision of transcriptome or mass spectrometry-based approaches for epitope discovery in autoimmunity, viral infection and cancer. Our data showing ribosome docking at alternative position within the INS transcript and CTL immunoreactivity against the N-term part of the INS DRIP polypeptide, while this epitope could not be eluted from previous peptide elution study (23). Though the human beta cell line are different (ECN90 vs EndoC-BH1/A2) these results emphasize the need to combine transcriptomic/ribosome profiling approaches with immunopeptidomic for epitope discovery. Despite the fact that translation initiation can be regulated by the secondary RNA structure (favoring some transcripts)(40), the results presented here, show that beta-cells may generate up to 22670 novel ORFs potentially immunogenic out of the 15014 start sites identified, assuming a minimal 9-mer residue core for HLA class I peptide. Of note, 9aa ORFs can be presented without further processing as shown for the METAAAVAA peptide derived from a 5'UTR ORF of ARAF protein, eluted as an intact peptide from HLA-B45 in previous study (41) and identified in our database. Although our data largely expand the peptide pool generated by beta-cells and potentially presented at the cell surface, their pathological significance remains to be determined. Certainly, the extreme sensitivity and specificity of CD8 cells to recognize pHLA complexes (42) could explain how the expression of rare peptides can drive an immune response and break tolerance in T1D. This process still remains poorly understood.

Despite remarkable improvement regarding sensitivity, mass spectrometry may not suffice for the identification of short-lived unstable proteins, or for proteins containing many cleavage sites for trypsin that is commonly used in sample preparation. Moreover, biases created by the input 
database and low EPCOT scores of out- of-frame sequences may hamper DRIP discovery. Nearly $40 \%$ of the overall initiation footprints derived from events of non-canonical translation may generate neo-polypeptides (not in frame sequences), even in resting beta-cells. These findings are consistent with other studies on mouse embryonic stem cells and healthy tissues deriving from hepatocellular carcinoma patients(29; 43). Our data demonstrate that an inflammatory environment led to significant increases in transcripts bearing more than one translation start in beta-cells, alike during tumorigenesis(43). The impact of inflammation on alternative start sites within transcripts encoding for ribosomal subunit proteins (RPL17, RPL35A, RPL37A) may suggest a role in the regulation of the translational process or in the assembly of the ribosome complex that could impact on the generation of immunoribosomes and production of $\operatorname{DRiPs}(44) \cdot(45)$. In line with other ribosome profiling studies, the 5'-UTR entailed a high proportion of footprints $(16 ; 29 ; 30 ; 46)$. Inflammation induced further upstream translation, highlighting this region as a potentially interesting source for the generation of neoantigens or small regulatory peptides. Besides the difference in amount of uTIS, treatment with inflammatory cytokines caused a shift versus CUG translation compared to the control. Previous studies have shown that CUG translation is mediated by a dedicated Leu-tRNA and EIF2a initiation factor(47), and has been widely correlated with a variety of stressors, like proteotoxic and oxidative stress, viral infection and treatment with Type I and Type II interferons $(17 ; 48)$. Moreover, CUG initiated polypeptides gave rise to highly immunogenic epitopes (e.g. cryptic antigens originating from VEGFA, bearing an alternative CTG ORFs have already been reported in ENSEMBL database and studied in the context of renal cell carcinoma)(17; 36; 49).

While in our data the classical AUG represent a minority of TIS, these results are in line with previous ribosome profiling studies. Yet, the conservation of a $\mathrm{G}$ in -3 and +1 position underlines 
the importance of the Kozak consensus sequence in initiating the translation. Recent work aiming at evaluating the strength of start codons has demonstrated that non-AUG codon located within a Kozak-like surrounding sequence may led to higher translation rates than a non-Kozak AUG(50). Polypeptides arising from these non-AUG alternative starts may not necessarily initiate with nonmethionine amino acids since eIF2a methionine carrying tRNA loading on non-AUG starting codon has been provided by in vitro assays using $\left[{ }^{35} \mathrm{~S}\right]$-labeled Met-tRNA ${ }_{i}{ }^{\mathrm{Met}}(51 ; 52)$. Also, some findings from ribosome profiling experiments have been confirmed by mass spectrometry(53), in particular N-term extension of annotated proteins.

Non-canonical TIS were not only present on coding transcripts, we observed that $7 \%$ of the footprints originated from various forms of presumably non-coding RNAs, especially lncRNAs. Several studies have confirmed the presence of ribosome attached to lncRNA suggesting the synthesis of small polypeptides (http://www.sorfs.org/database). The absence of epitopes in these polypeptides suggests a regulatory function(54).

The study relies on the use of EndoC- $\beta \mathrm{H} 1$ cells as an in vitro model for human beta cells. While, those cells have been described to represent the best alternative so far to primary human beta cells and, as such, constitutes a relevant "humanized" model to study beta cell function (in particular EndoC- $\beta \mathrm{H} 1$ cells and human islets have very similar responses to cytokines and other stressors(5558), recent, in depth multiomics analyses have highlighted some differences between EndoC- $\beta \mathrm{H} 1$ cells and primary beta cells(59)), (e.g. the absence of iNOS expression in response to cytokines(60)), inherent to both the fetal/embryonic origin of the cell line and/or its transformed state. The presence of ribosomes bound to glucagon transcripts in our study may be the reflect of this observation. Another limitation is intrinsic to the ribosome profiling assay, in which a number of identified start sites may be the consequence of monosome footprint or background artifacts. 
Yet, despite very stringent detection method (that exclude robust interpretation of ribosome reads at IAPP,GAD65,ZnT8 and IGRP start position), future follow up studies to validate the identified polypeptides, presented here, are required to define the missing fraction of the beta cell proteome. Altogether, our results reveal that the translation process plays a significant role in proteome diversity. While some of these peptides synthesized by beta-cells may prove unstable and lacking biological functions, they may represent by-products of the translation process that can contribute to the beta-cell translatome. The fact that translation is highly dynamic and affected by environmental modifications suggests that perturbations occurring on beta-cells at the onset of disease or throughout the course of T1D may change the beta-cell ligandome, generating neoepitopes provoking immune surveillance. Currently, drugs are being developed to inhibit non canonical translation initiation(61), which may offer strategies to control beta-cell homeostasis, immunogenicity and preservation.

Novel non canonical open reading frames warrant further functional and immunological studies. We contend that understanding mechanisms of neoantigen generation is critical for the development of novel immune targeted therapies.

Acknowledgments: The authors want to thank Dr. Fabio Lauria (Institute of Biophysics - Trento) and Ruben van 't Slot (UMC Utrecht) for technical assistance.This work is supported by JDRF, DON and the Dutch Diabetes Research Foundation and by the IMI2-JU under grant agreement No 115797 (INNODIA) and No 945268 (INNODIA HARVEST). This Joint Undertaking receives support from the Union's Horizon 2020 research and innovation program and "EFPIA", 'JDRF" 
and "The Leona M. and Harry B. Helmsley Charitable Trust". BOR is supported by the Wanek Family Project for Type 1 Diabetes.

Author contributions: S.T., A,S., R.S., A.M.G, F.C. performed the experiments and wrote the manuscript, S.T, R.S., J.B, F.M., L.H, B.K. analyzed the data, R.C.H. and B.O.R wrote the manuscript, H.M. supervised data analysis, AZ supervised the project and wrote the manuscript. AZ is the guarantor of this work and, as such, had full access to all the data in the study and takes responsibility for the integrity of the data and the accuracy of the data analysis.

Competing interests: The authors declare no competing interests.

Data and materials availability: All data needed to evaluate the conclusions in the paper are present in the paper and the Supplementary Materials. Raw datasets are accessible through GEO series accession number

GSE167223

(https://www.ncbi.nlm.nih.gov/geo/query/acc.cgi?acc=GSE167223). All data files (S1-S9) are accessible at $\underline{10.6084 / \mathrm{m} 9 . \text { figshare. } 13187714 .}$ 


\section{REFERENCES}

1. Coppieters KT, Dotta F, Amirian N, Campbell PD, Kay TW, Atkinson MA, Roep BO, von Herrath MG: Demonstration of islet-autoreactive CD8 T cells in insulitic lesions from recent onset and long-term type 1 diabetes patients. J Exp Med 2012;209:51-60

2. Pinkse GG, Tysma OH, Bergen CA, Kester MG, Ossendorp F, van Veelen PA, Keymeulen B, Pipeleers D, Drijfhout JW, Roep BO: Autoreactive CD8 T cells associated with beta cell destruction in type 1 diabetes. Proc Natl Acad Sci U S A 2005;102:18425-18430

3. Skowera A, Ellis RJ, Varela-Calvino R, Arif S, Huang GC, Van-Krinks C, Zaremba A, Rackham C, Allen JS, Tree TI, Zhao M, Dayan CM, Sewell AK, Unger WW, Drijfhout JW, Ossendorp F, Roep BO, Peakman M: CTLs are targeted to kill beta cells in patients with type 1 diabetes through recognition of a glucose-regulated preproinsulin epitope. J Clin Invest 2008;118:3390-3402

4. Abreu JR, Martina S, Verrijn Stuart AA, Fillie YE, Franken KL, Drijfhout JW, Roep BO: CD8 T cell autoreactivity to preproinsulin epitopes with very low human leucocyte antigen class I binding affinity. Clin Exp Immunol 2012;170:57-65

5. Eizirik DL, Colli ML, Ortis F: The role of inflammation in insulitis and beta-cell loss in type 1 diabetes. Nat Rev Endocrinol 2009;5:219-226

6. O'Sullivan-Murphy B, Urano F: ER stress as a trigger for beta-cell dysfunction and autoimmunity in type 1 diabetes. Diabetes 2012;61:780-781

7. Thomaidou S, Kracht MJL, van der Slik A, Laban S, de Koning EJ, Carlotti F, Hoeben RC, Roep BO, Zaldumbide A: beta-Cell Stress Shapes CTL Immune Recognition of Preproinsulin Signal Peptide by Posttranscriptional Regulation of Endoplasmic Reticulum Aminopeptidase 1. Diabetes 2020;69:670-680

8. de Jong VM, Zaldumbide A, van der Slik AR, Persengiev SP, Roep BO, Koeleman BP: Post-transcriptional control of candidate risk genes for type 1 diabetes by rare genetic variants. Genes Immun 2013;14:58-61 9. Eizirik DL, Sammeth M, Bouckenooghe T, Bottu G, Sisino G, Igoillo-Esteve M, Ortis F, Santin I, Colli ML, Barthson J, Bouwens L, Hughes L, Gregory L, Lunter G, Marselli L, Marchetti P, McCarthy MI, Cnop M: The human pancreatic islet transcriptome: expression of candidate genes for type 1 diabetes and the impact of pro-inflammatory cytokines. PLoS Genet 2012;8:e1002552

10. Delong T, Wiles TA, Baker RL, Bradley B, Barbour G, Reisdorph R, Armstrong M, Powell RL, Reisdorph N, Kumar N, Elso CM, DeNicola M, Bottino R, Powers AC, Harlan DM, Kent SC, Mannering SI, Haskins K: Pathogenic CD4 T cells in type 1 diabetes recognize epitopes formed by peptide fusion. Science 2016;351:711-714

11. McLaughlin RJ, de Haan A, Zaldumbide A, de Koning EJ, de Ru AH, van Veelen PA, van Lummel M, Roep BO: Human islets and dendritic cells generate post-translationally modified islet autoantigens. Clin Exp Immunol 2016;185:133-140

12. Roep BO, Kracht MJ, van Lummel M, Zaldumbide A: A roadmap of the generation of neoantigens as targets of the immune system in type 1 diabetes. Curr Opin Immunol 2016;43:67-73

13. Kracht MJL, Zaldumbide A, Roep BO: Neoantigens and Microenvironment in Type 1 Diabetes: Lessons from Antitumor Immunity. Trends Endocrinol Metab 2016;27:353-362

14. Gerashchenko MV, Lobanov AV, Gladyshev VN: Genome-wide ribosome profiling reveals complex translational regulation in response to oxidative stress. Proc Natl Acad Sci U S A 2012;109:17394-17399

15. Vattem KM, Wek RC: Reinitiation involving upstream ORFs regulates ATF4 mRNA translation in mammalian cells. Proc Natl Acad Sci U S A 2004;101:11269-11274

16. Lee S, Liu B, Lee S, Huang SX, Shen B, Qian SB: Global mapping of translation initiation sites in mammalian cells at single-nucleotide resolution. Proc Natl Acad Sci U S A 2012;109:E2424-2432 
17. Prasad S, Starck SR, Shastri N: Presentation of Cryptic Peptides by MHC Class I Is Enhanced by Inflammatory Stimuli. J Immunol 2016;197:2981-2991

18. Yewdell JW: DRiPs solidify: progress in understanding endogenous MHC class I antigen processing. Trends Immunol 2011;32:548-558

19. Starck SR, Shastri N: Non-conventional sources of peptides presented by MHC class I. Cell Mol Life Sci 2011;68:1471-1479

20. Saulquin X, Scotet E, Trautmann L, Peyrat MA, Halary F, Bonneville M, Houssaint E: +1 Frameshifting as a novel mechanism to generate a cryptic cytotoxic $T$ lymphocyte epitope derived from human interleukin 10. J Exp Med 2002;195:353-358

21. Yewdell JW, Anton LC, Bennink JR: Defective ribosomal products (DRiPs): a major source of antigenic peptides for MHC class I molecules? J Immunol 1996;157:1823-1826

22. Kracht MJ, van Lummel M, Nikolic T, Joosten AM, Laban S, van der Slik AR, van Veelen PA, Carlotti $F$, de Koning EJ, Hoeben RC, Zaldumbide A, Roep BO: Autoimmunity against a defective ribosomal insulin gene product in type 1 diabetes. Nat Med 2017;23:501-507

23. Gonzalez-Duque S, Azoury ME, Colli ML, Afonso G, Turatsinze JV, Nigi L, Lalanne AI, Sebastiani G, Carre A, Pinto S, Culina S, Corcos N, Bugliani M, Marchetti P, Armanet M, Diedisheim M, Kyewski B, Steinmetz LM, Buus S, You S, Dubois-Laforgue D, Larger E, Beressi JP, Bruno G, Dotta F, Scharfmann R, Eizirik DL, Verdier Y, Vinh J, Mallone R: Conventional and Neo-antigenic Peptides Presented by beta Cells Are Targeted by Circulating Naive CD8+ T Cells in Type 1 Diabetic and Healthy Donors. Cell Metab 2018;28:946960 e946

24. Ravassard P, Hazhouz Y, Pechberty S, Bricout-Neveu E, Armanet M, Czernichow P, Scharfmann R: A genetically engineered human pancreatic beta cell line exhibiting glucose-inducible insulin secretion. J Clin Invest 2011;121:3589-3597

25. Ingolia NT, Brar GA, Rouskin S, McGeachy AM, Weissman JS: The ribosome profiling strategy for monitoring translation in vivo by deep sequencing of ribosome-protected mRNA fragments. Nat Protoc 2012;7:1534-1550

26. FRESNO M, JIMÉNEZ A, VÁZQUEZ DJEjob: Inhibition of translation in eukaryotic systems by harringtonine. 1977;72:323-330

27. Lauria F, Tebaldi T, Bernabò P, Groen EJ, Gillingwater TH, Viero GJPcb: riboWaltz: Optimization of ribosome P-site positioning in ribosome profiling data. 2018;14:e1006169

28. Wan J, Qian SB: TISdb: a database for alternative translation initiation in mammalian cells. Nucleic Acids Res 2014;42:D845-850

29. Ingolia NT, Lareau LF, Weissman JS: Ribosome profiling of mouse embryonic stem cells reveals the complexity and dynamics of mammalian proteomes. Cell 2011;147:789-802

30. Ji Z, Song R, Regev A, Struhl K: Many IncRNAs, 5'UTRs, and pseudogenes are translated and some are likely to express functional proteins. Elife 2015;4:e08890

31. Lu G, Hao X, Chen WH, Mu S: GAAD: A Gene and Autoimmiune Disease Association Database. Genomics Proteomics Bioinformatics 2018;16:252-261

32. Martens GA, Jiang L, Hellemans KH, Stange G, Heimberg H, Nielsen FC, Sand O, Van Helden J, Van Lommel L, Schuit F, Gorus FK, Pipeleers DG: Clusters of conserved beta cell marker genes for assessment of beta cell phenotype. PLoS One 2011;6:e24134

33. Russell MA, Redick SD, Blodgett DM, Richardson SJ, Leete $P$, Krogvold L, Dahl-Jorgensen K, Bottino R, Brissova M, Spaeth JM, Babon JAB, Haliyur R, Powers AC, Yang C, Kent SC, Derr AG, Kucukural A, Garber MG, Morgan NG, Harlan DM: HLA Class II Antigen Processing and Presentation Pathway Components Demonstrated by Transcriptome and Protein Analyses of Islet beta-Cells From Donors With Type 1 Diabetes. Diabetes 2019;68:988-1001

34. Gerashchenko MV, Lobanov AV, Gladyshev VN: Genome-wide ribosome profiling reveals complex translational regulation in response to oxidative stress. 2012;109:17394-17399 
35. Jiang Z, Yang J, Dai A, Wang Y, Li W, Xie ZJBg: Ribosome profiling reveals translational regulation of mammalian cells in response to hypoxic stress. 2017;18:1-12

36. Weinzierl AO, Maurer D, Altenberend F, Schneiderhan-Marra N, Klingel K, Schoor O, Wernet D, Joos T, Rammensee HG, Stevanovic S: A cryptic vascular endothelial growth factor T-cell epitope: identification and characterization by mass spectrometry and T-cell assays. Cancer Res 2008;68:2447-2454

37. Thomaidou S, Zaldumbide A, Roep BO: Islet stress, degradation and autoimmunity. Diabetes Obes Metab 2018;20 Suppl 2:88-94

38. Kanatsuna N, Taneera J, Vaziri-Sani F, Wierup N, Larsson HE, Delli A, Skarstrand H, Balhuizen A, Bennet $H$, Steiner DF, Torn C, Fex M, Lernmark A: Autoimmunity against INS-IGF2 protein expressed in human pancreatic islets. J Biol Chem 2013;288:29013-29023

39. Casellas A, Mallol C, Salavert A, Jimenez V, Garcia M, Agudo J, Obach M, Haurigot V, Vila L, Molas M, Lage R, Morro M, Casana E, Ruberte J, Bosch F: Insulin-like Growth Factor 2 Overexpression Induces betaCell Dysfunction and Increases Beta-cell Susceptibility to Damage. J Biol Chem 2015;290:16772-16785

40. Mustoe AM, Busan S, Rice GM, Hajdin CE, Peterson BK, Ruda VM, Kubica N, Nutiu R, Baryza JL, Weeks KM: Pervasive Regulatory Functions of mRNA Structure Revealed by High-Resolution SHAPE Probing. Cell 2018;173:181-195 e118

41. Ouspenskaia T, Law T, Clauser KR, Klaeger S, Sarkizova S, Aguet F, Li B, Christian E, Knisbacher BA, Le PM, Hartigan CR, Keshishian H, Apffel A, Oliveira G, Zhang W, Chow YT, Ji Z, Jungreis I, Shukla SA, Bachireddy P, Kellis M, Getz G, Hacohen N, Keskin DB, Carr SA, Wu CJ, Regev A: Thousands of novel unannotated proteins expand the MHC I immunopeptidome in cancer. 2020:2020.2002.2012.945840

42. George AJ, Stark J, Chan C: Understanding specificity and sensitivity of T-cell recognition. Trends Immunol 2005;26:653-659

43. Zou Q, Xiao Z, Huang $R$, Wang $X$, Wang $X$, Zhao $H$, Yang $X$ : Survey of the translation shifts in hepatocellular carcinoma with ribosome profiling. Theranostics 2019;9:4141-4155

44. Wei J, Yewdell JW: Immunoribosomes: Where's there's fire, there's fire. Mol Immunol 2019;113:38-

42

45. Wei J, Kishton RJ, Angel M, Conn CS, Dalla-Venezia N, Marcel V, Vincent A, Catez F, Ferre S, Ayadi L, Marchand V, Dersh D, Gibbs JS, Ivanov IP, Fridlyand N, Coute Y, Diaz JJ, Qian SB, Staudt LM, Restifo NP, Yewdell JW: Ribosomal Proteins Regulate MHC Class I Peptide Generation for Immunosurveillance. Mol Cell 2019;73:1162-1173 e1165

46. Machkovech HM, Bloom JD, Subramaniam AR: Comprehensive profiling of translation initiation in influenza virus infected cells. PLoS Pathog 2019;15:e1007518

47. Starck SR, Jiang V, Pavon-Eternod M, Prasad S, McCarthy B, Pan T, Shastri N: Leucine-tRNA initiates at CUG start codons for protein synthesis and presentation by MHC class I. Science 2012;336:1719-1723

48. Yewdell JW, Holly J: DRiPs get molecular. Curr Opin Immunol 2020;64:130-136

49. Schwab SR, Shugart JA, Horng T, Malarkannan S, Shastri N: Unanticipated antigens: translation initiation at CUG with leucine. PLoS Biol 2004;2:e366

50. Diaz de Arce AJ, Noderer WL, Wang CL: Complete motif analysis of sequence requirements for translation initiation at non-AUG start codons. Nucleic Acids Res 2018;46:985-994

51. Peabody DS: Translation initiation at an ACG triplet in mammalian cells. J Biol Chem 1987;262:1184711851

52. Liang $H$, Chen $X$, Yin $Q$, Ruan $D$, Zhao $X$, Zhang $C$, McNutt MA, Yin Y: PTENbeta is an alternatively translated isoform of PTEN that regulates rDNA transcription. Nat Commun 2017;8:14771

53. Na CH, Barbhuiya MA, Kim MS, Verbruggen S, Eacker SM, Pletnikova O, Troncoso JC, Halushka MK, Menschaert G, Overall CM, Pandey A: Discovery of noncanonical translation initiation sites through mass spectrometric analysis of protein N termini. Genome Res 2018;28:25-36 
54. Jackson R, Kroehling L, Khitun A, Bailis W, Jarret A, York AG, Khan OM, Brewer JR, Skadow MH, Duizer C, Harman CCD, Chang L, Bielecki P, Solis AG, Steach HR, Slavoff S, Flavell RA: The translation of noncanonical open reading frames controls mucosal immunity. Nature 2018;564:434-438

55. Brozzi F, Nardelli TR, Lopes M, Millard I, Barthson J, Igoillo-Esteve M, Grieco FA, Villate O, Oliveira JM, Casimir M, Bugliani M, Engin F, Hotamisligil GS, Marchetti P, Eizirik DL: Cytokines induce endoplasmic reticulum stress in human, rat and mouse beta cells via different mechanisms. Diabetologia 2015;58:23072316

56. Coomans de Brachene A, Dos Santos RS, Marroqui L, Colli ML, Marselli L, Mirmira RG, Marchetti P, Eizirik DL: IFN-alpha induces a preferential long-lasting expression of $\mathrm{MHC}$ class I in human pancreatic beta cells. Diabetologia 2018;61:636-640

57. Marroqui L, Dos Santos RS, Op de Beeck A, Coomans de Brachene A, Marselli L, Marchetti P, Eizirik DL: Interferon-alpha mediates human beta cell HLA class I overexpression, endoplasmic reticulum stress and apoptosis, three hallmarks of early human type 1 diabetes. Diabetologia 2017;60:656-667

58. Tsonkova VG, Sand FW, Wolf XA, Grunnet LG, Kirstine Ringgaard A, Ingvorsen C, Winkel L, Kalisz M, Dalgaard K, Bruun C, Fels JJ, Helgstrand C, Hastrup S, Oberg FK, Vernet E, Sandrini MPB, Shaw AC, Jessen C, Gronborg M, Hald J, Willenbrock H, Madsen D, Wernersson R, Hansson L, Jensen JN, Plesner A, Alanentalo T, Petersen MBK, Grapin-Botton A, Honore C, Ahnfelt-Ronne J, Hecksher-Sorensen J, Ravassard $\mathrm{P}$, Madsen OD, Rescan C, Frogne T: The EndoC-betaH1 cell line is a valid model of human beta cells and applicable for screenings to identify novel drug target candidates. Mol Metab 2018;8:144-157

59. Lawlor N, Marquez EJ, Orchard P, Narisu N, Shamim MS, Thibodeau A, Varshney A, Kursawe R, Erdos MR, Kanke M, Gu H, Pak E, Dutra A, Russell S, Li X, Piecuch E, Luo O, Chines PS, Fuchbserger C, Center NIHIS, Sethupathy P, Aiden AP, Ruan Y, Aiden EL, Collins FS, Ucar D, Parker SCJ, Stitzel ML: Multiomic Profiling Identifies cis-Regulatory Networks Underlying Human Pancreatic beta Cell Identity and Function. Cell Rep 2019;26:788-801 e786

60. Oleson BJ, McGraw JA, Broniowska KA, Annamalai M, Chen J, Bushkofsky JR, Davis DB, Corbett JA, Mathews CE: Distinct differences in the responses of the human pancreatic beta-cell line EndoC-betaH1 and human islets to proinflammatory cytokines. Am J Physiol Regul Integr Comp Physiol 2015;309:R525534

61. Kearse MG, Wilusz JE: Non-AUG translation: a new start for protein synthesis in eukaryotes. Genes Dev 2017;31:1717-1731 
Table 1. Primer sequences used to generate the RPF library.

\begin{tabular}{|c|c|c|}
\hline & & Primers sequences $\left(5^{\prime}->3^{\prime}\right)$ \\
\hline \multirow[t]{2}{*}{$\begin{array}{c}\text { Size } \\
\text { markers }\end{array}$} & $\begin{array}{l}\text { Upper size } \\
\text { marker }\end{array}$ & AUGUACACGGAGUCGAGCUCAACCCGCAACGCGA-(Phos) \\
\hline & $\begin{array}{l}\text { Lower size } \\
\text { marker }\end{array}$ & AUGUACACGGAGUCGACCCAACGCGA-(Phos) \\
\hline Linker & $\begin{array}{l}\text { Universal } \\
\text { miRNA } \\
\text { cloning } \\
\text { linker }\end{array}$ & rAppCTGTAGGCACCATCAAT-NH2 \\
\hline CDNA & $\begin{array}{l}\text { Reverse } \\
\text { transcripti } \\
\text { on }\end{array}$ & $\begin{array}{c}\text { (Phos)- } \\
\text { AGATCGGAAGAGCGTCGTGTAGGGAAAGATGTAGATCTCGGTGGTCGC- } \\
\text { (SpC18)-CACTCA- } \\
\text { (SpC18)- TTCAGACGTGTGCTCTTCCGATCTATTGATGGTGCCTACAG }\end{array}$ \\
\hline \multirow[t]{14}{*}{ Purification } & $\begin{array}{c}\text { rRNA } \\
\text { depletion }\end{array}$ & GGGGGGATGCGTGCATTTATCAGATCA \\
\hline & & TTGGTGACTCTAGATAACCTCGGGCCGATCGCACG \\
\hline & & GAGCCGCCTGGATACCGCAGCTAGGAATAATGGAAT \\
\hline & & TCGTGGGGGGCCCAAGTCCTTCTGATCGAGGCCC \\
\hline & & GCACTCGCCGAATCCCGGGGCCGAGGGAGCGA \\
\hline & & GGGGCCGGGCCGCCCCTCCCACGGCGCG \\
\hline & & GGGGCCGGGCCACCCCTCCCACGGCGCG \\
\hline & & CCCAGTGCGCCCCGGGCGTCGTCGCGCCGTCGGGTCCCGGG \\
\hline & & TCCGCCGAGGGCGCACCACCGGCCCGTCTCGCC \\
\hline & & AGGGGCTCTCGCTTCTGGCGCCAAGCGT \\
\hline & & GAGCCTCGGTTGGCCCCGGATAGCCGGGTCCCCGT \\
\hline & & GAGCCTCGGTTGGCCTCGGATAGCCGGTCCCCCGC \\
\hline & & TCGCTGCGATCTATTGAAAGTCAGCCCTCGACACA \\
\hline & & TCCTCCCGGGGCTACGCCTGTCTGAGCGTCGCT \\
\hline \multirow{5}{*}{$\begin{array}{c}\text { Library } \\
\text { preparatio } \\
n\end{array}$} & $\begin{array}{l}\text { Forward } \\
\text { library PCR }\end{array}$ & AATGATACGGCGACCACCGAGATCTACAC \\
\hline & $\begin{array}{c}\text { Index } \\
\text { reverse } \\
\text { library PCR }\end{array}$ & $\begin{array}{l}\text { CAAGCAGAAGACGGCATACGAGATAGTCGTGTGACTGGAGTTCAGACGTGTE } \\
\text { CTCTTCCG }\end{array}$ \\
\hline & & $\begin{array}{l}\text { CAAGCAGAAGACGGCATACGAGATACTGATGTGACTGGAGTTCAGACGTGTG } \\
\text { CTCTTCCG }\end{array}$ \\
\hline & & $\begin{array}{l}\text { CAAGCAGAAGACGGCATACGAGATATGCTGGTGACTGGAGTTCAGACGTGTG } \\
\text { CTCTTCCG }\end{array}$ \\
\hline & & $\begin{array}{l}\text { CAAGCAGAAGACGGCATACGAGATACGTCGGTGACTGGAGTTCAGACGTGTG } \\
\text { CTCTTCCG }\end{array}$ \\
\hline
\end{tabular}




\section{FIGURE LEGENDS}

Figure 1: Ribosome profiling of EndoC- $\beta$ H1. (A) Schematic representation of experimental workflow. (B) Length distribution of ribosomal footprints of non-treated (control) and IFN $\gamma+$ IL1 $\beta$ treated samples (cytokines) $(\mathrm{n}=3)(\mathbf{C})$ Venn diagram of P-sites identified in control and cytokines treated samples. The total number of genes carrying a TIS and the total number of TIS are indicated as $\sum$ (D) Qualitative sequence logo of codons composition corresponding to E- (-3 to 0$)$, P-(0 to 3) and A-(3 to 6) pockets of the ribosome.

Figure 2: Mapping of TIS on the transcriptome. (A) Gene ontology plot of canonical TIS (cpm> $0.5)$, showing significant $\log$ fold change compared to the control $(\log \mathrm{FC}>1.5)$. The plot was generated using clusterProfiler (B) Heatmap of the canonical TIS (cpm>0.5) significantly up- or down-regulated in cytokines treated samples. The heatmap was generated using Pheatmap. (C) Pie charts representing the percentage of alternative and annotated TIS in experimental conditions. (D) Pie charts representing the abundance percentage of the different types of ORFs derived from the alternative TIS represented in C. (E) Pie charts of TIS identified in coding and non-coding RNA. (F) Polar plots of non-coding transcripts subtypes, showing one or more TIS. (G) Length of ORFs potentially generated by the identified TIS. The average length of the ORFs is indicated as $\mu$.

Figure 3: Integration of long RNA sequencing and Ribosome profiling. (A) Mean percentages of ribosomal footprints aligned to the transcriptome $(\mathrm{n}=3)$. (B) Nanopore QC analysis showing the RNA read length. The cleaned reads were aligned to the transcriptome (ENSEMBL build GRCh38.99) for the controls ( $\mathrm{n}=3)$ and cytokine treated samples $(\mathrm{n}=3)$ using STAR version 2.7.3a (C) Volcano plot of transcripts expression detected in long RNA sequencing ( $\mathrm{n}=3$, read cut off: 
mean of replicates=10). T1D susceptible genes are depicted on the figure. (D) Venn diagram representing the novel transcripts detected in control and cytokine treated conditions. (E) Venn diagram representing the number of TIS detected on novel transcripts (shown in D), upon alignment of Ribosome profiling with long RNA sequencing data. (F) Codon usage of TIS on novel transcripts. Sequence logo, corresponding to E- (-3 to 0), P-(0 to 3) and A-(3 to 6) sites of the ribosome pockets. (G) Length of ORFs potentially generated by the identified TIS on novel transcripts. The average length of the ORFs is indicated as $\mu$. (H) Scatterplot representing the differential expression of the RPF at TIS position (x) versus differential expression of the long RNA sequencing transcripts (y). T1D susceptible genes are depicted on the figure.

Figure 4: Inflammation disturbs the translational process and fidelity. (A) Percentage of transcripts showing a unique or multiple TIS (two or more). Statistical analysis was performed using the z-score test. (B) Region distribution of the TIS identified on the transcriptome in control or cytokine treated conditions. Statistical analysis was performed using the z-score test. (C) Qualitative codon usage profiles of upstream and downstream the canonical start codon. Sequence logo, corresponding to E- (-3 to 0$), \mathrm{P}-(0$ to 3$)$ and A-(3 to 6) sites of the ribosome pockets. (D) Volcano plot of the out of frame TIS differential expression per transcript regions. (E) Scatterplot representing the differential expression of the RPF at canonical TIS position versus differential expression of the out of frame alternative TIS. Spearman correlation test was used to calculate the $\mathrm{R}$ factor and the corresponding P-value. T1D susceptible genes are labelled on the figures.

Figure 5: TIS and aTIS within INS transcripts. (A) TIS positioned on the INS transcript (ENST00000381330). The red arrow indicate the position of the INS286. Primers used for RT-PCR 
are indicated as primer set 1. (B) Schematic representation of the INS, INS-IGF2 transcripts detected by long RNA sequencing. Newly identified transcripts are labelled as "TALONT". The arrows indicate the canonical start site (black) and the $\operatorname{INS}_{286}$ (red) (left panel). RT PCR performed on EndoC- $\beta \mathrm{H} 1$ RNA and primary islet isolated RNA using TALON specific primers and sequence analysis of the PCR amplicon (C) TIS mapping of the INS-IGF295 TIS on the novel INS-IGF2 transcript, TALONT000499153. The INS-DRIP epitope is underlined. The sequence in red show the new potential HLA-A2 epitope predicted from the INS-IGF2 polypeptide. (D) Killing assay performed on JY cells loaded with PPi peptide, B chain peptide and DRiP peptide using DRiP specific CD8 T cells. T cell activation is shown as CD107a staining (left panel) and MIP1 $\beta$ release (right panel). (E) HLA-A/B/C expression in EndoC-BH1/HLA-A2 upon treatment (upper panel) and HLA-A2 expression in EndoC-BH1 and EndoC-BH1/HLA-A2 cells (lower panel). (F) EndoC- $\beta \mathrm{H} 1$ and EndoC- $\beta \mathrm{H} 1 / \mathrm{HLA}-\mathrm{A} 2$ coculture with DRiP specific CD8 T cells after incubation with cytokines (IFNy and IL1 $\beta$ ) for $24 \mathrm{~h}$ ( $\mathrm{n}=3$ independent experiments). $\mathrm{T}$ cell activation is shown as CD107a staining (left panel) and MIP1 $\beta$ release (right panel). 


\section{SUPPLEMENTARY FIGURE LEGENDS}

Figure S1: Harringtonine treatment optimization. (A) Example of the bell shaped curve read distribution encountered at TIS locations (GAPDH transcript). (B) Metaplots of reads distribution around the annotated start and stop codons after 2' (upper) or 30' (lower) harringtonine treatment (C) Metaheatmaps of the density of extremities of sequenced footprint fragments around the annotated start after 2'(upper) or 30'(lower) harringtonine (D),(E) IGV browser screenshots of reads mapping on GAPDH and ACTB genes after 2'(upper) or 30'(lower) harringtonine. The small boxes depict the UTRs, the large boxes the CDS, and the dashed lines the intronic region.

Figure S2: Enrichment algorithm. (A) Schematic representation of enrichment algorithm applied on the Ribowaltz output. (B) Example for HLA-B transcripts showing potential TIS distribution before (upper) and after (lower) applying the enrichment algorithm. The orange bar colour indicate an increased enrichment upon cytokine stimulation.

Figure S3: Protein validation. CHGA, STAT1, STAT2, PSMB8, PSMB9 and PSMB10 expression level in EndoC- $\beta \mathrm{H} 1$ cells (A) and primary human islets (B) after exposure to cytokine (IFNy and IL1 $\beta$ ). Protein quantification is performed using ImageJ and shown as relative expression using actin as reference. n.d. indicate no detected band. *indicate the immunoproteasome subunit position. The blots shown are representative of 2 independent experiments (2 islet preparations). 
Figure S4: Examples of TIS mapping. (A),(B) TAP1 and PSMD8 TIS profiling. $x$ axes represent transcript location. $\mathrm{X}=0$ shows the annotated translation start. Arrows indicate the detected main TIS, consistent with the TIDdb database. Orange bars show TIS significantly upregulated upon cytokine treatment. (C),(D) YBX1 and PGRMC1 TIS profiling. $\mathrm{x}$ axes represent transcript location. $\mathrm{X}=0$ shows the annotated translation start. Arrows indicate TIS detected by mass spectrometry(53). The orange bars show TIS significantly upregulated upon cytokine treatment. Internal in frame TIS are not depicted in all graphs. (E,F) TIS mapping on CHGA and VEGF transcripts. The orange bars show TIS significantly upregulated upon cytokine treatment. The ORFs' amino-acid sequence based on the upregulated TIS are shown in the table below. The aa highlighted in red indicate potential HLA-A2 binder based on NetMHCI prediction. $\mathrm{x}$ axes represent transcript location. $\mathrm{X}=0$ shows the annotated translation start.

Figure S5: Validation of the de novo transcriptome. A) Venn diagram showing the number of transcripts (table S4) supported by reads in splicing junction. B) Similar representation for T1D susceptible transcripts. From 6892 TALON transcripts, 3425 novel intronic junctions (and 212 novel intronic junctions in T1D susceptible genes specifically) were detected out of the 2305 intronic containing transcripts. By comparing datasets, 2550 intronic junctions (163 out of 212 novel introns detected in all T1D transcripts) were detected by Illumina bulk RNAseq. C) RT PCR performed on EndoC- $\beta \mathrm{H} 1$ RNA and primary islet isolated RNA using TALONT ALONT000709680 specific primers for detection of PSMB9 transcript variant. D) RT PCR performed on EndoC- $\beta$ H1 RNA and primary islet isolated RNA using TALONT000700063 specific primers for detection of HLA-C transcript variants. 
Figure S6: Inflammation disturbs the translational process and fidelity. Volcano plot representing the differential read expression at start site position in newly identified transcripts (A) and within non-coding RNA (B). T1D susceptible genes are depicted on the figures.

Figure S7: Pathway analysis of alternative start sites more upregulated than the corresponding canonical starts. Analysis performed by Stringdb at medium confidence and two k-mean clusters. The red nodes show proteins of the mRNA processing pathway, and the red-blue nodes show proteins specifically involved in mRNA splicing and located in stress granules. The combs colouring is based on the default String settings.

Figure S8: Characterization of the CHGA 5'-UTR region. A) Representation of the (AltCHGA)-GFP fusion construct. The 5'-UTR region of CHGA is represented as white box; the GFP ORF deleted from the AUG is shown as dark blue box; The CHGA canonical start site and its ORF are presented in blue. The Alt-CHGA-GFP ORF is represented in green and position of the in frame start sites $-103 ;-40$ and -22 are shown with black arrow. B) sequence of the (Alt-CHGA)GFP construct. C) GFP FACS profile of HEK 293 cells transfected with the (Alt-CHGA)-GFP or GFP (with AUG) constructs. D) Western blot analysis showing expression of the GFP fusion proteins after transfection in HEK 293 cells and cytokine stimulation. 0.5ug protein loaded of CMV-GFP transfected cells; 50ug protein loaded on of (Alt-CHGA)-GFP transfected cells. NT: non transfected; MW: molecular weight showing the bands at $37 \mathrm{kDa}$ and $25 \mathrm{kDa}$. Upper panel stained with anti-GFP antibody (* show unspecific band); Lower panel stained with anti-Actin antibody (uncut blots are presented as supplementary material) 


\section{Figure 1.}

A.

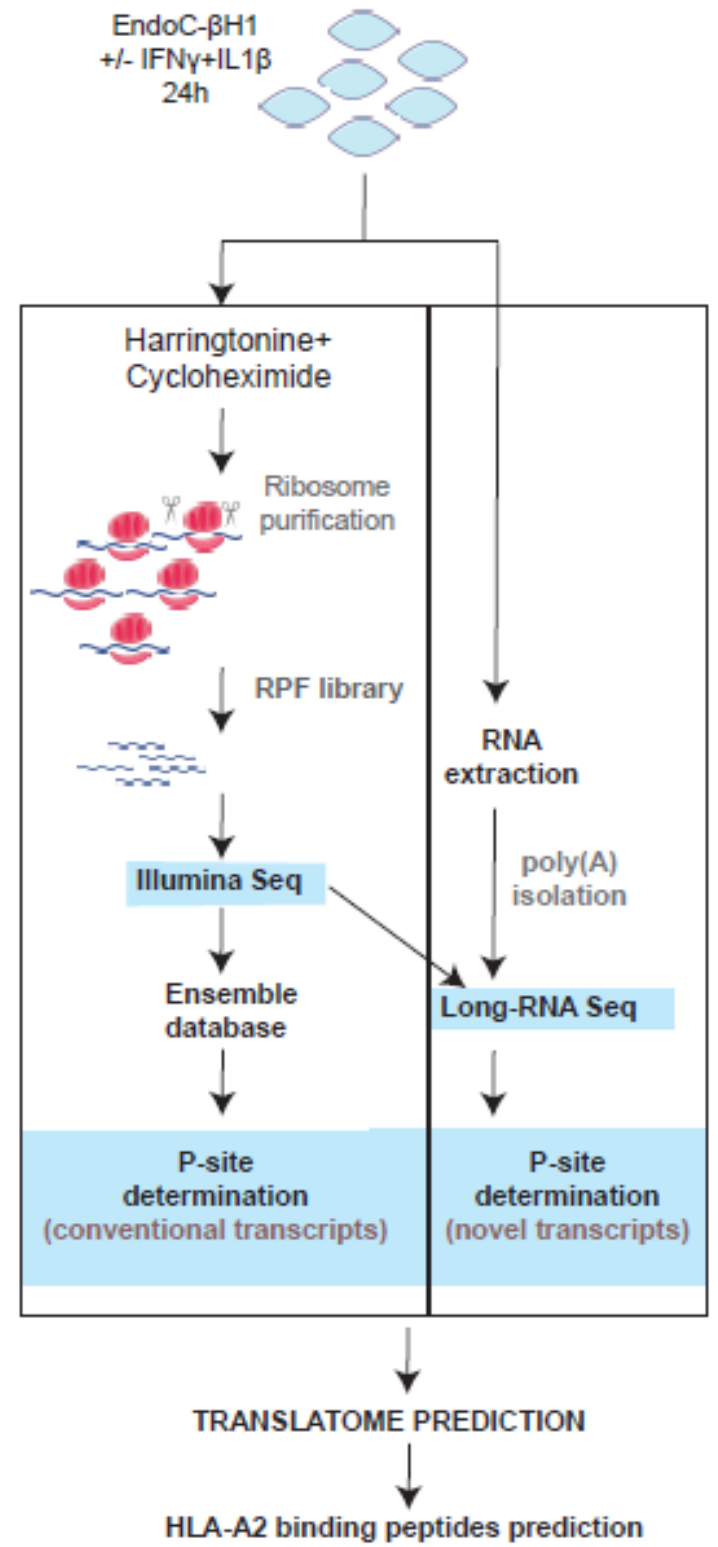

B.

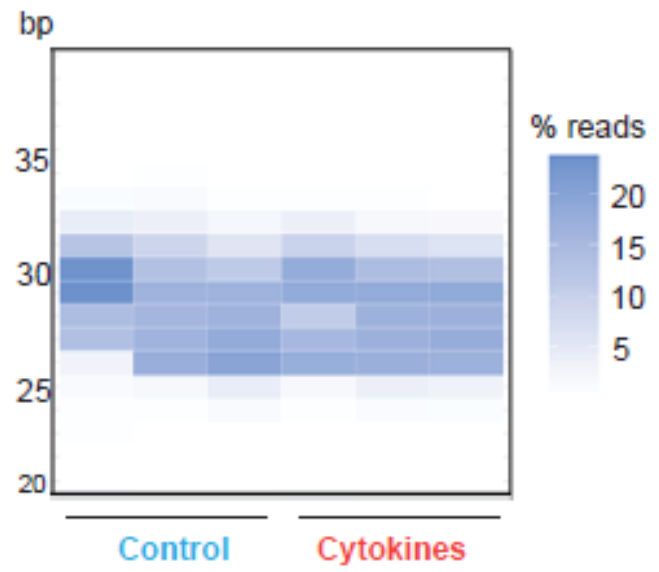

c.

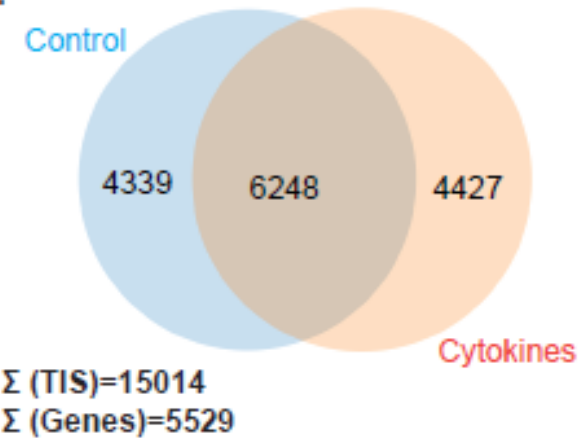

D.

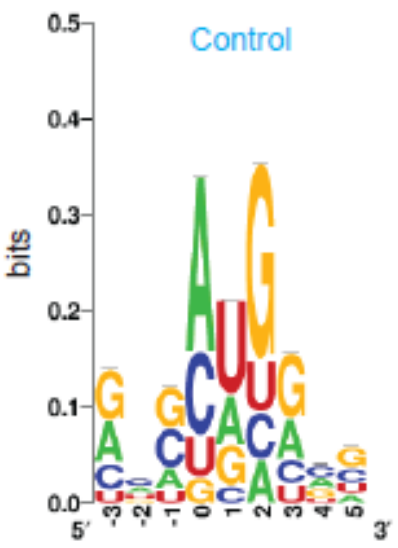

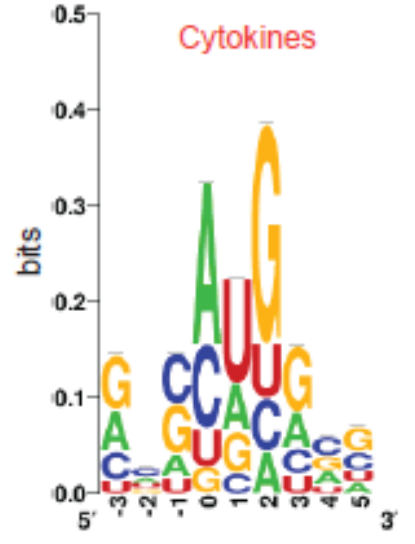


Figure 2.

A.

c.

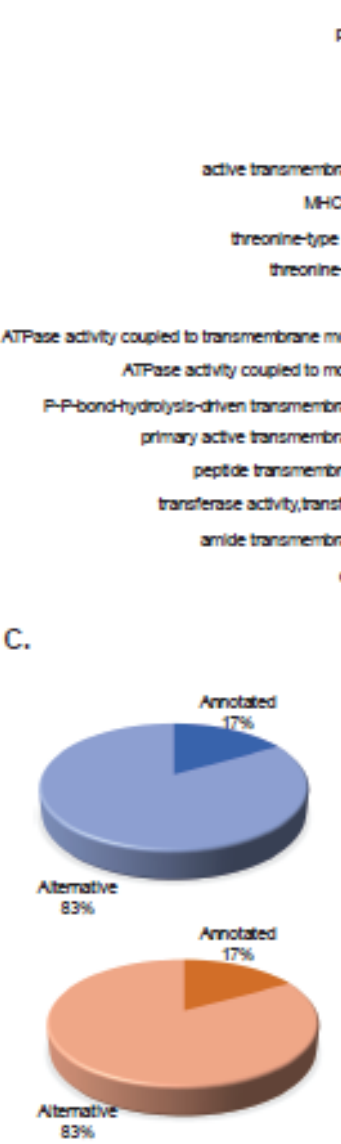

E.
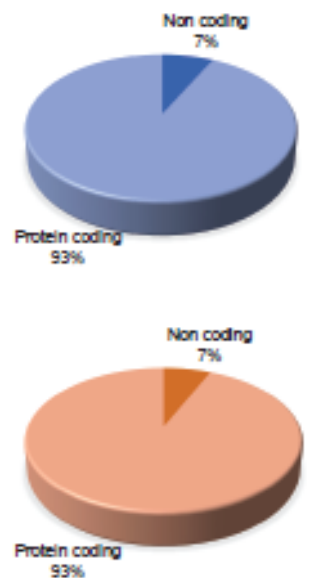

B.

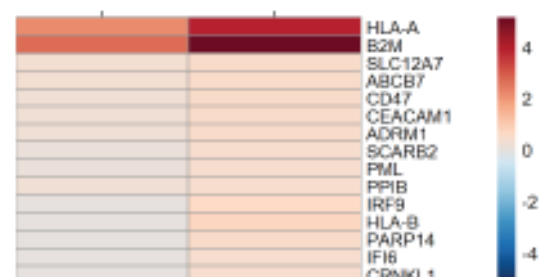
MHC protein binding

eeptide antoen binding artigen binding pegtide binding amide binding MC class I protein binding inetpe endopeptidase scthits verent of substance mentrone tranaporter acthity tomentrane troponter activty erave acthity, ranaferring pertogil groupa. trone transporter actiris oxdoredstare activity

D.
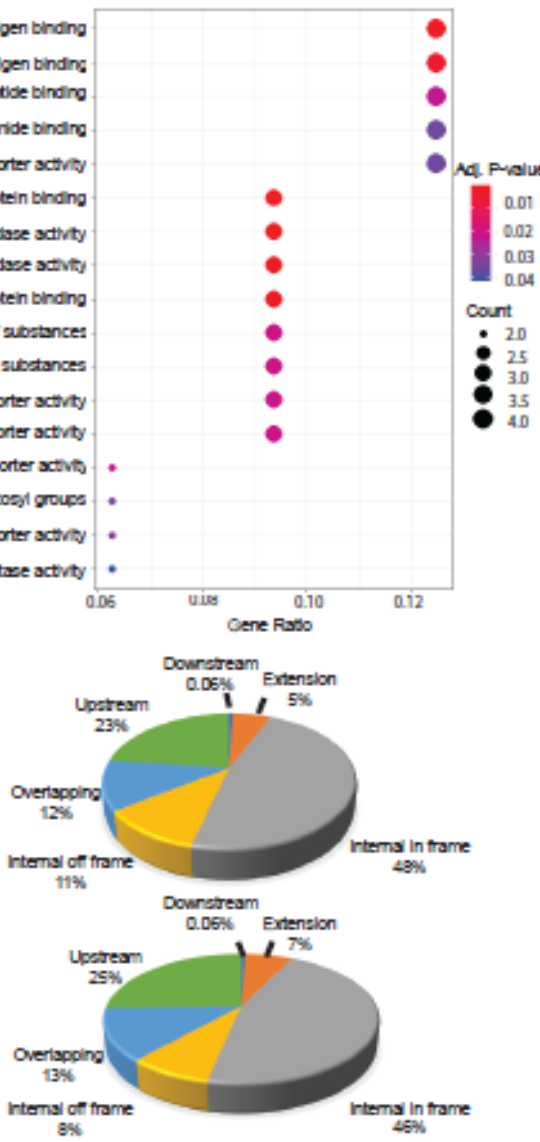

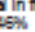

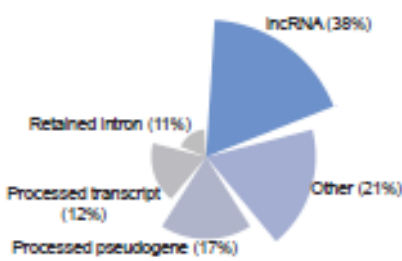

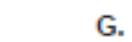

Gon cod
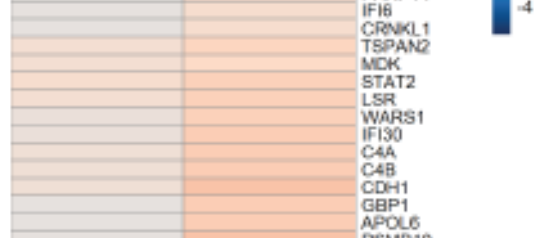

$C A B$
$C D H 1$

CDH1

APQLE

PSME
STAT1

TAPBP

TSC2203
UROD

TNFRSF 19

YPS26C

UNG

FXYOE

FXYDE-FXYD?

PXMP2

ATl1

CHOA

PSME1

MT2A

WARS1.1

KCTD12

KCTD12 12

FKBP1A

TAP2

ARF1
IRF

BATF2

HLA-E
TNFSF 10

PSMES

HLAC

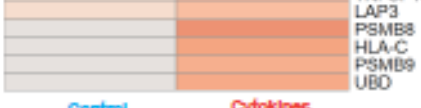

Control

Cytokinoc
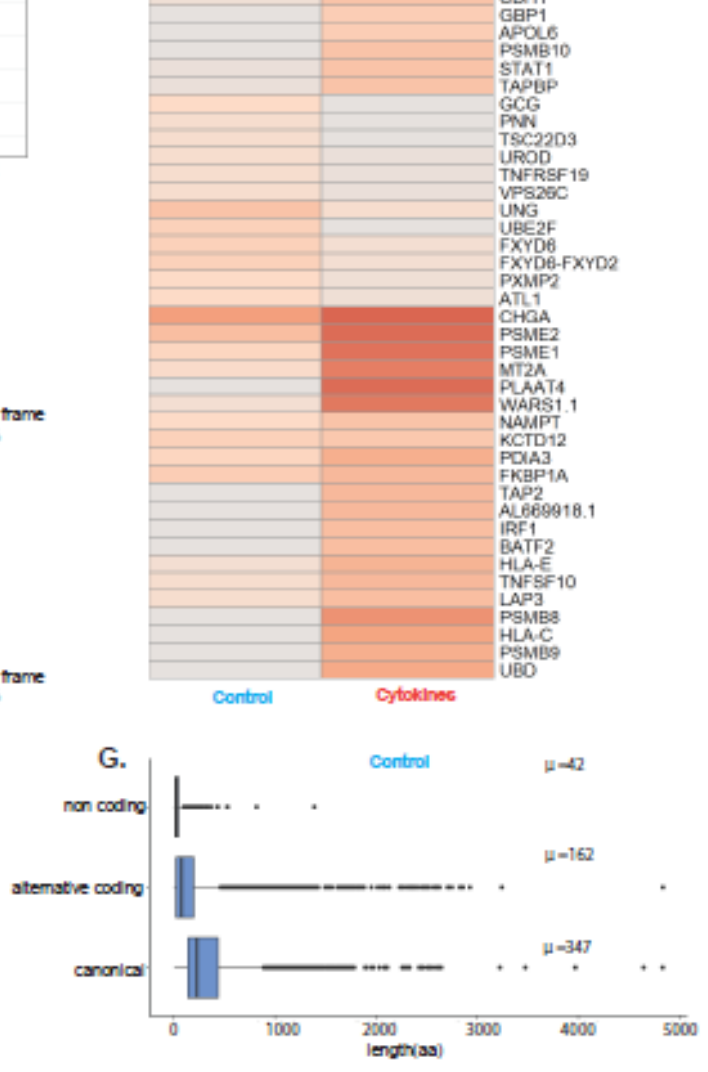
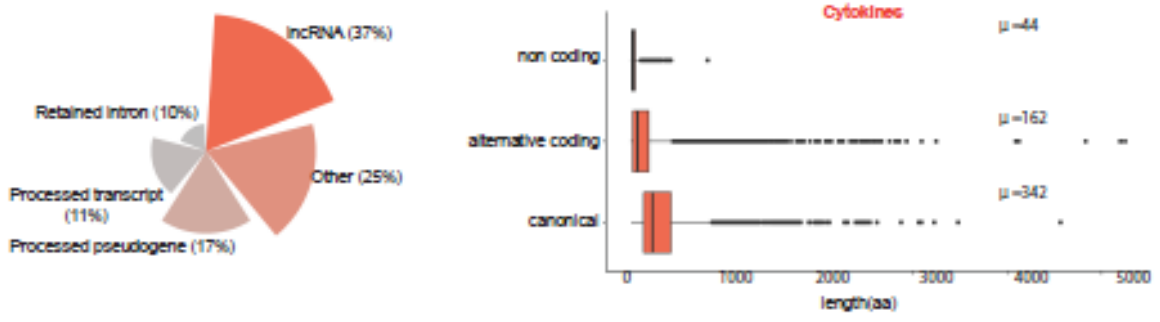
Figure 3.

A.

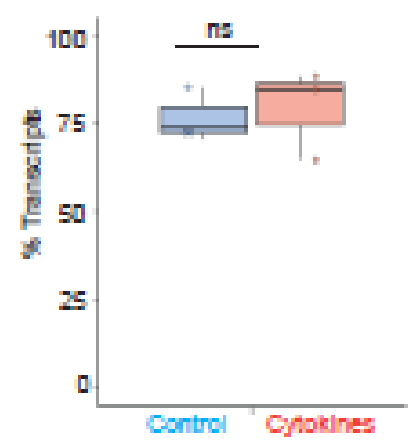

c.

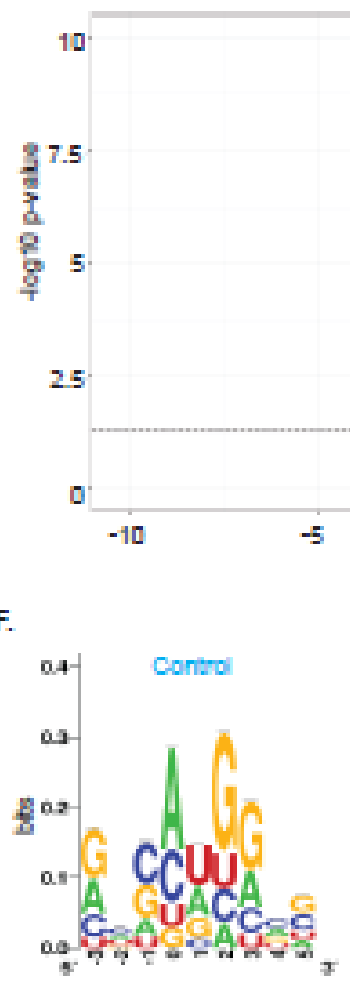

G.

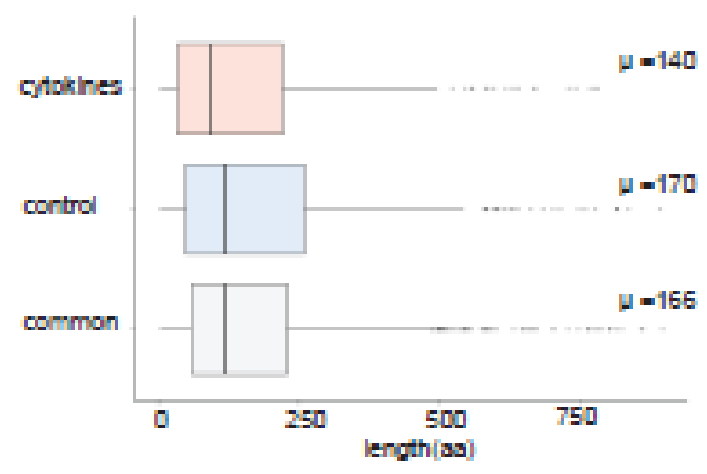

F.

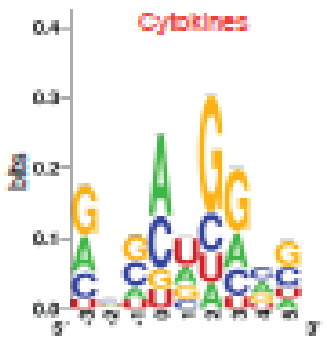

B.
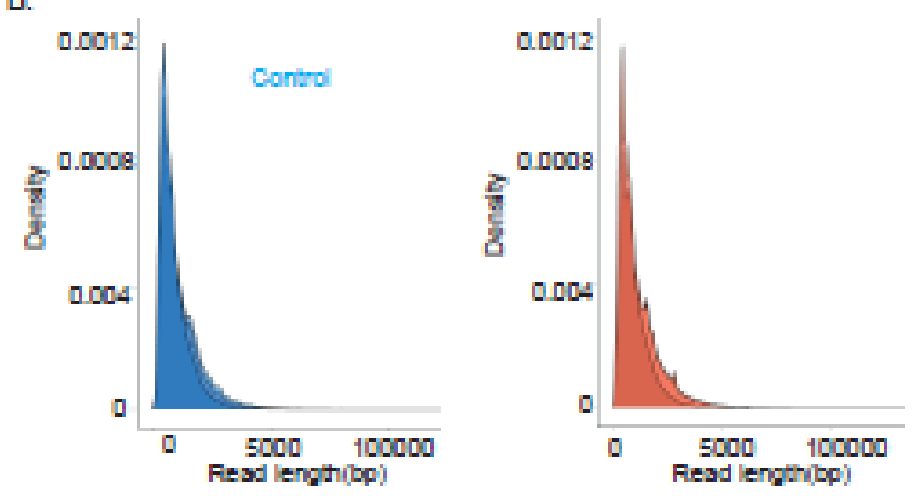

D.

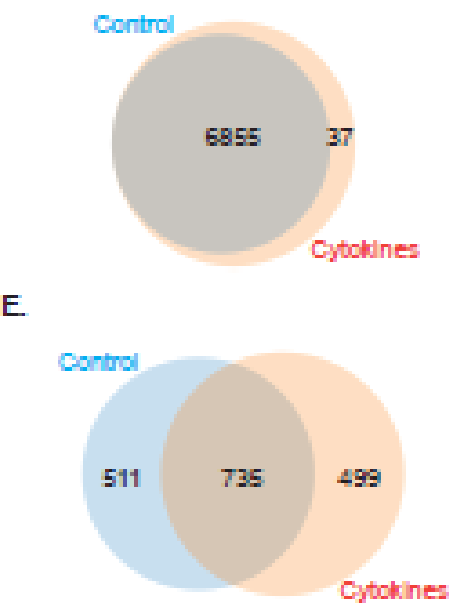

H.

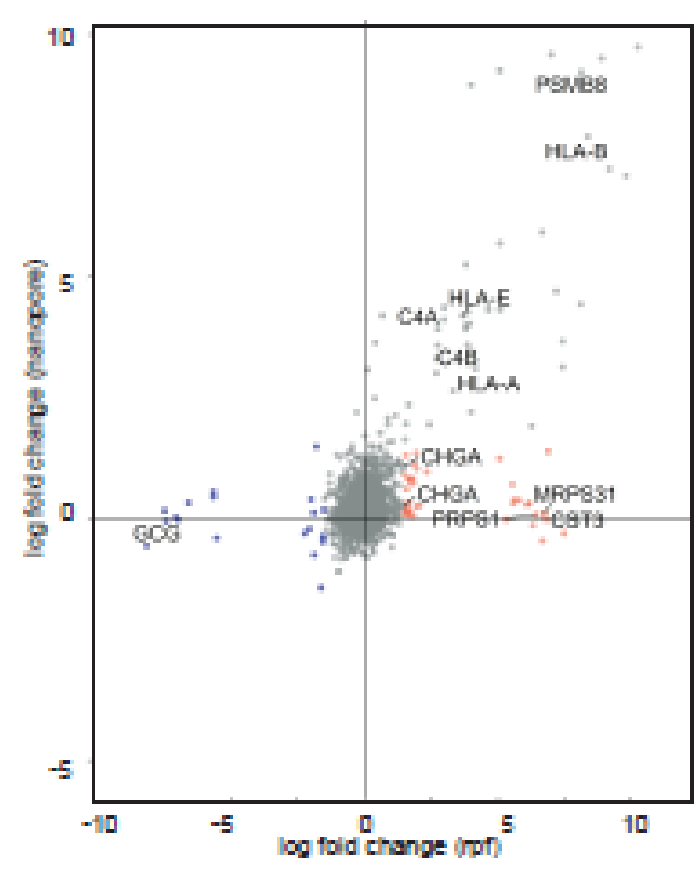


Figure 4 .

A.

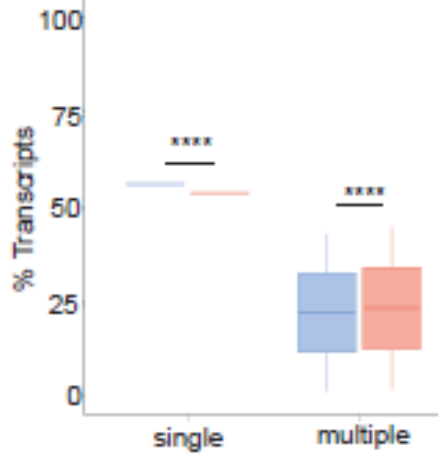

B.

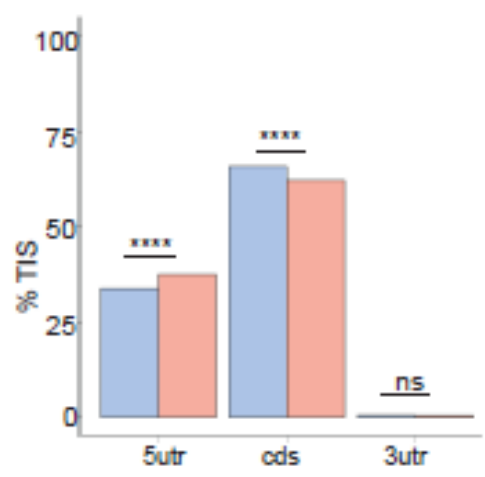

D.

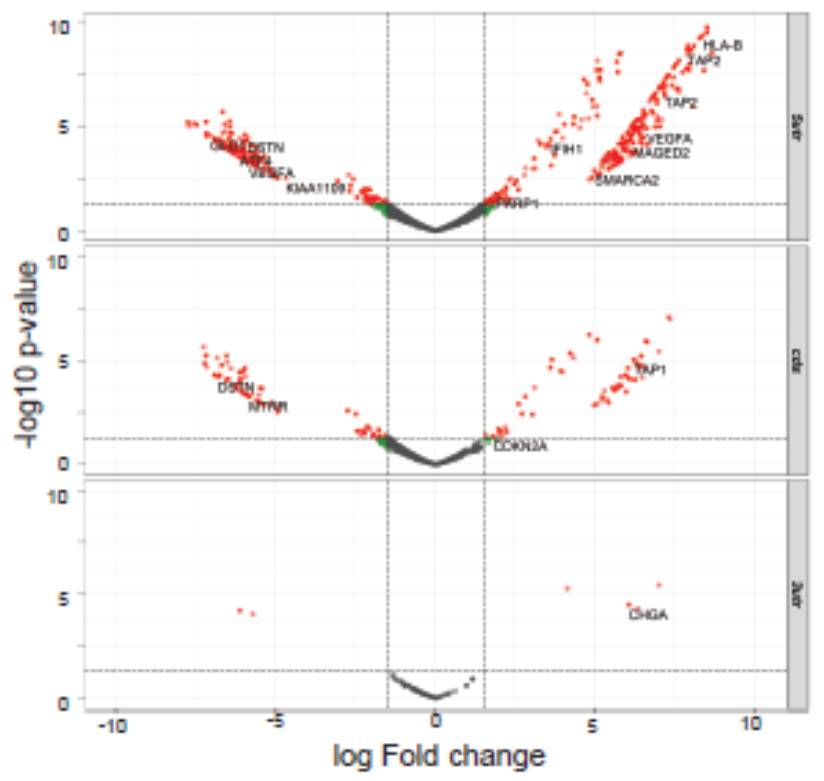

c.
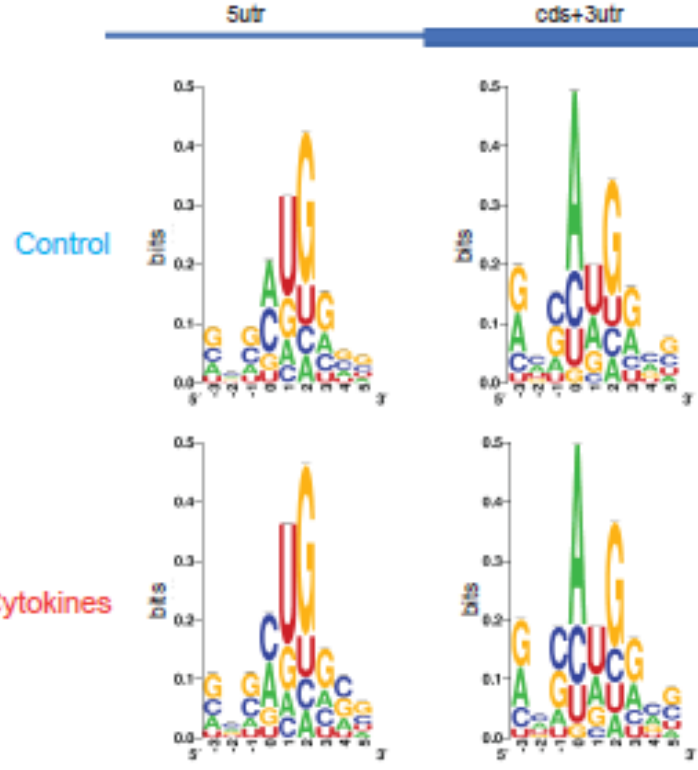

E.

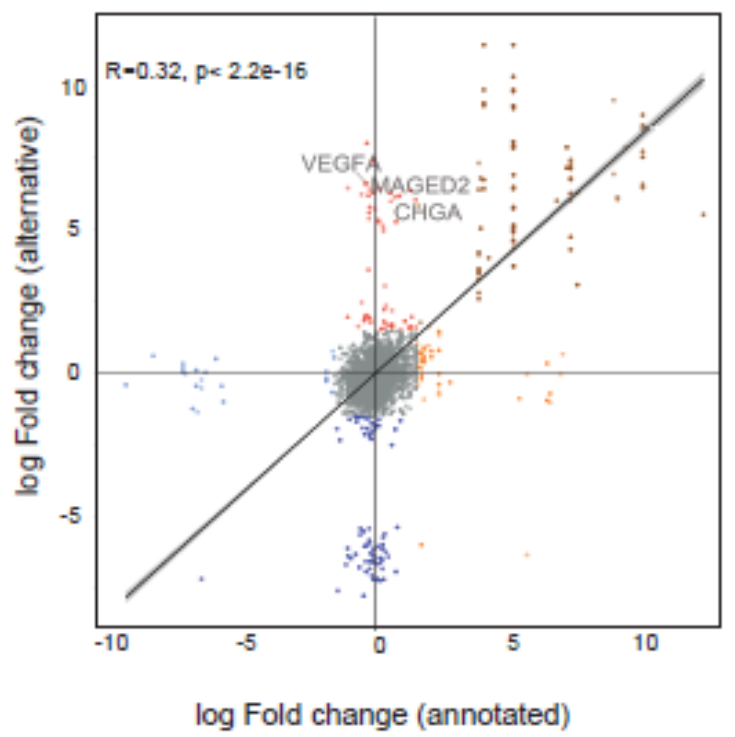


Figure S1.

A.

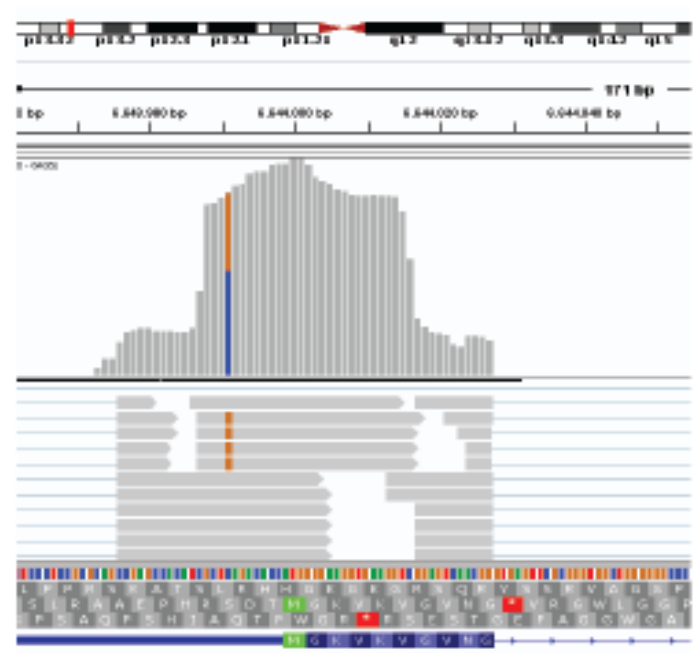

c.
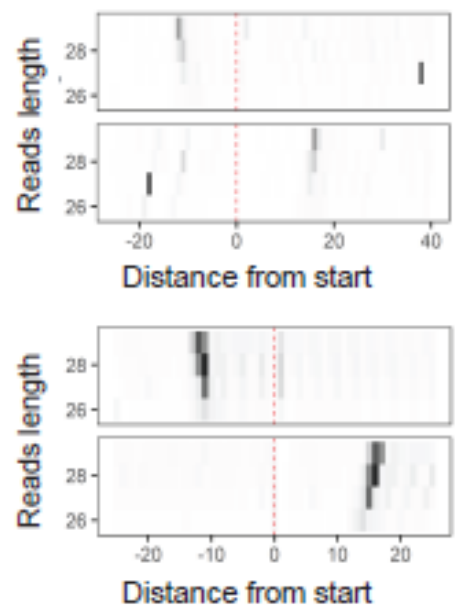

B.
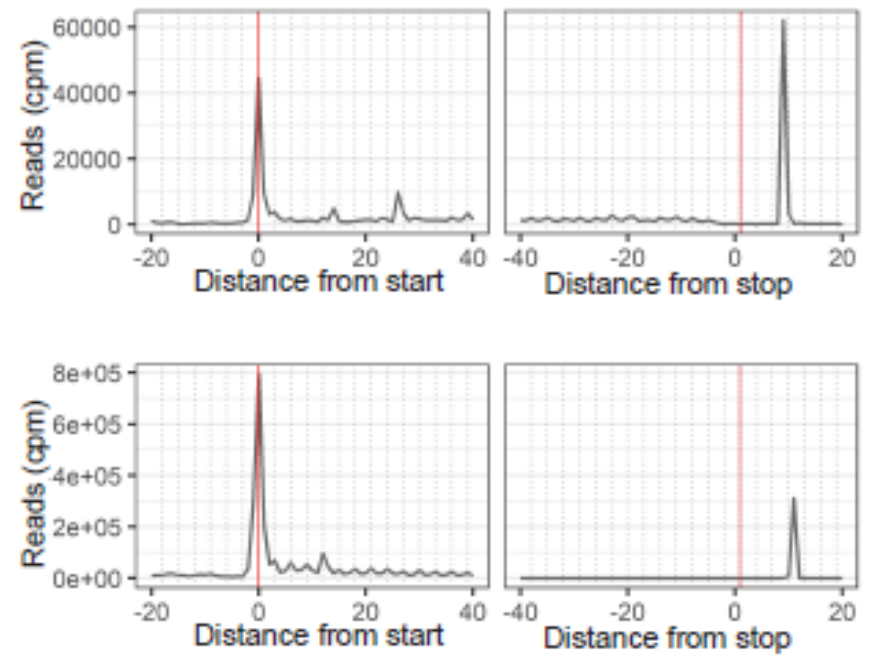

E.

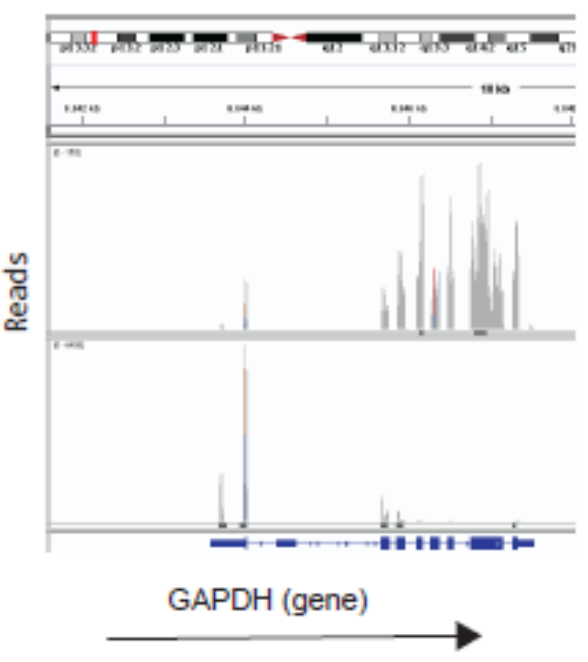

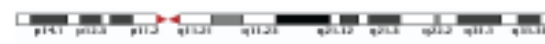
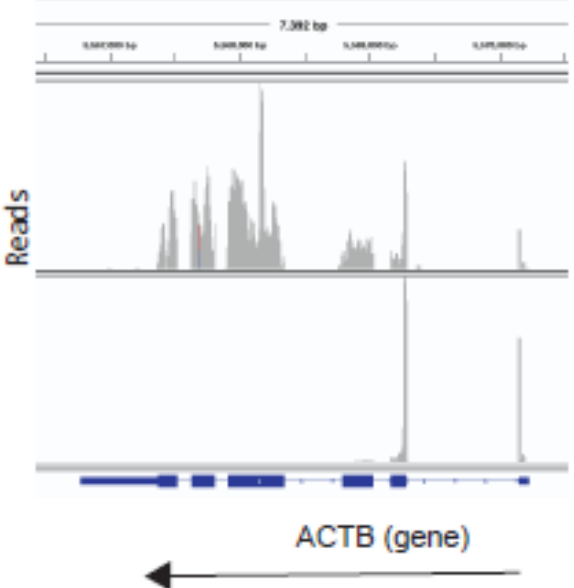
Figure S2.

A.

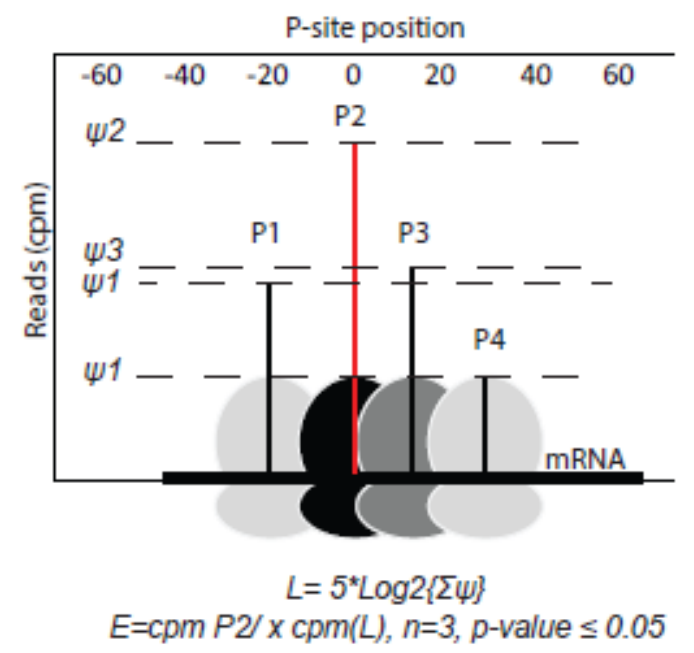

B.

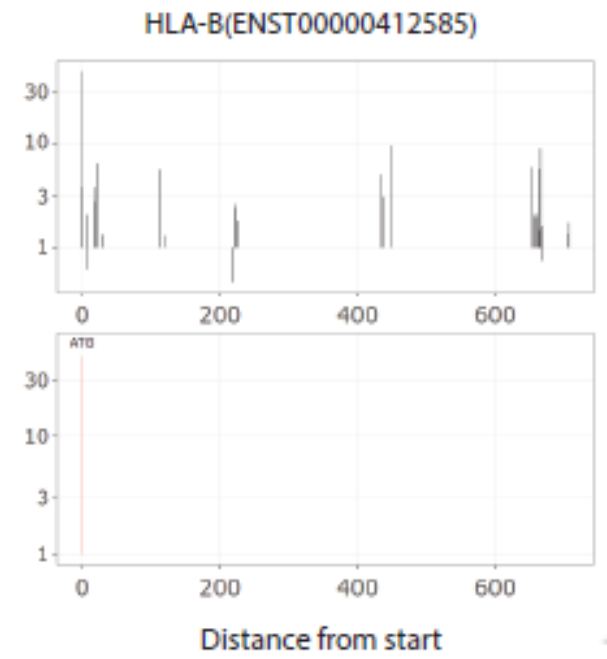


Supplementary Figure S3

A.
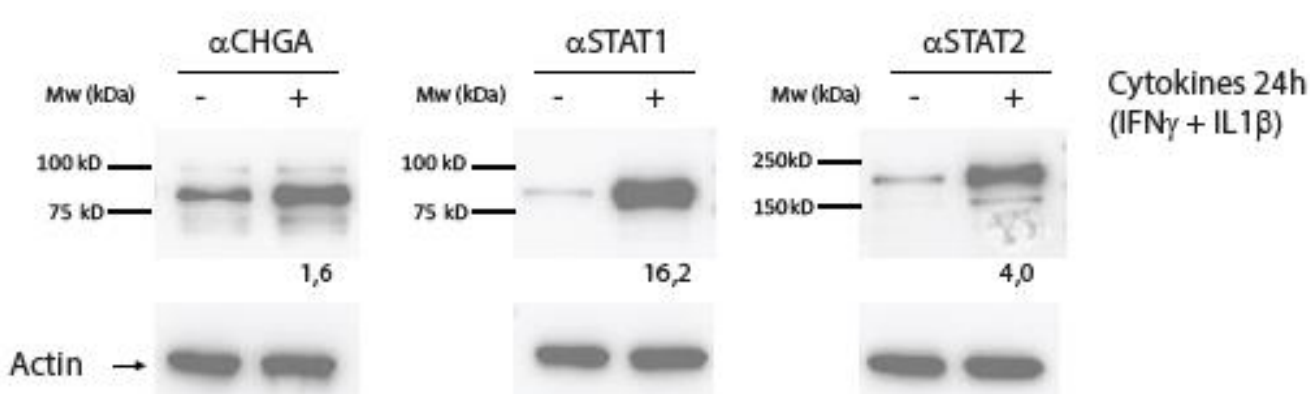

4,0
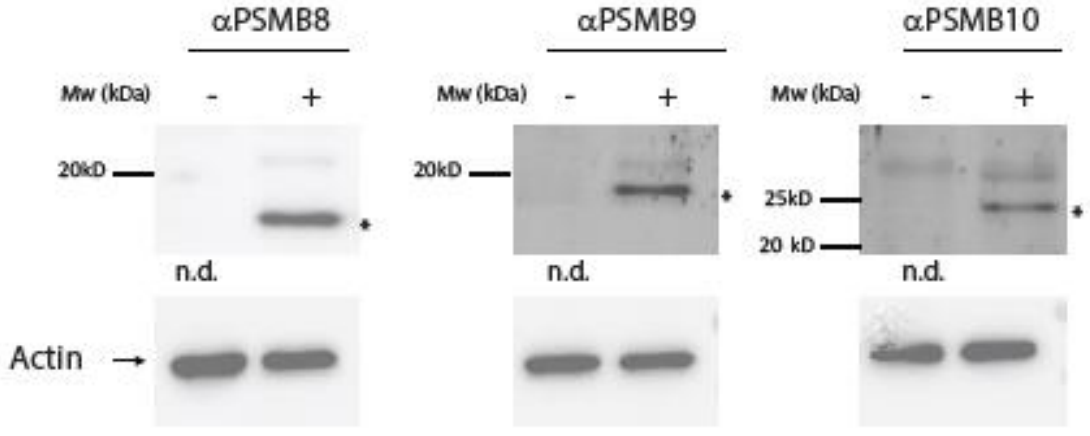

B.

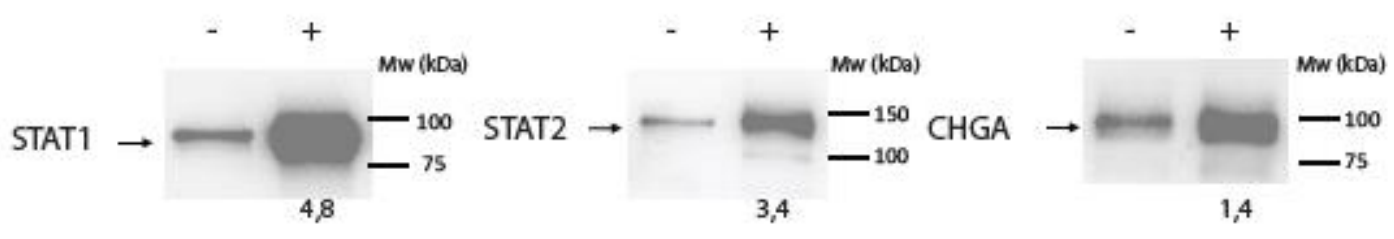

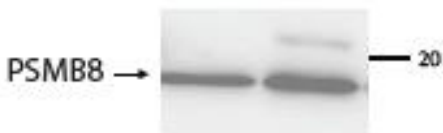

2,8

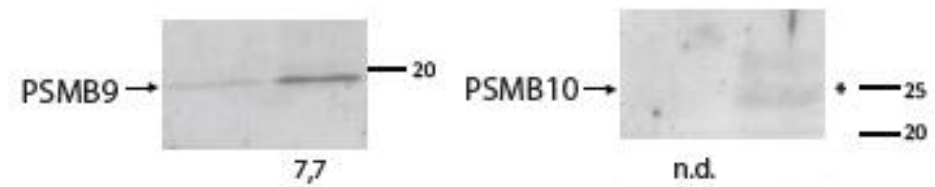

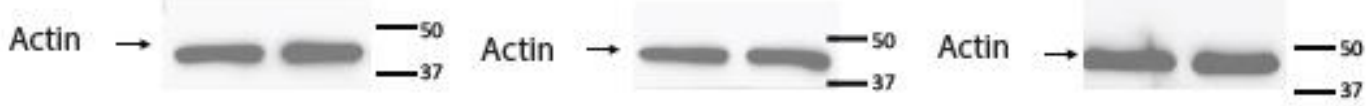


Figure s4.

A.

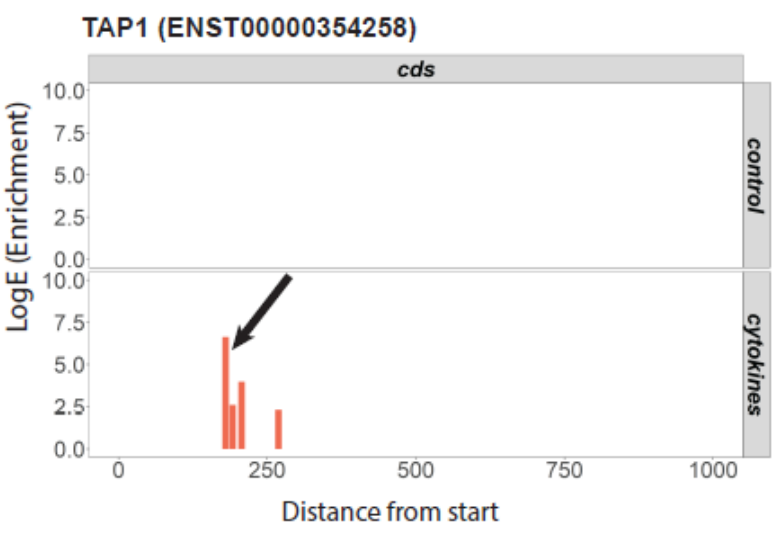

c.

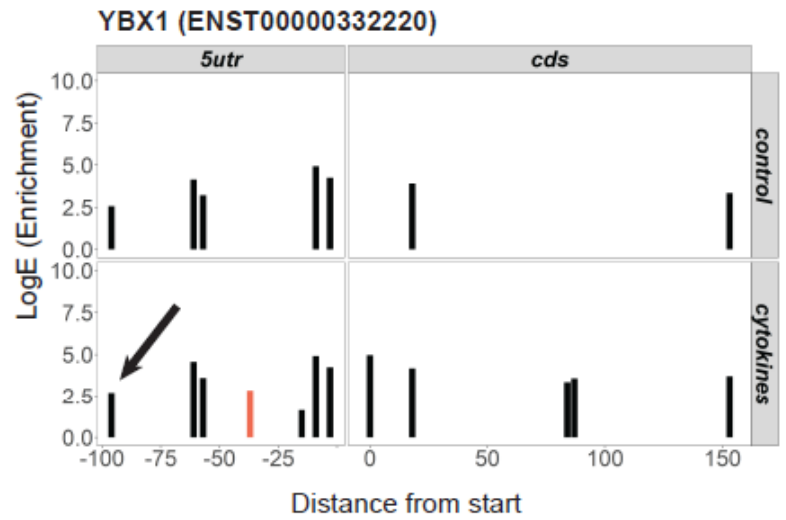

E.

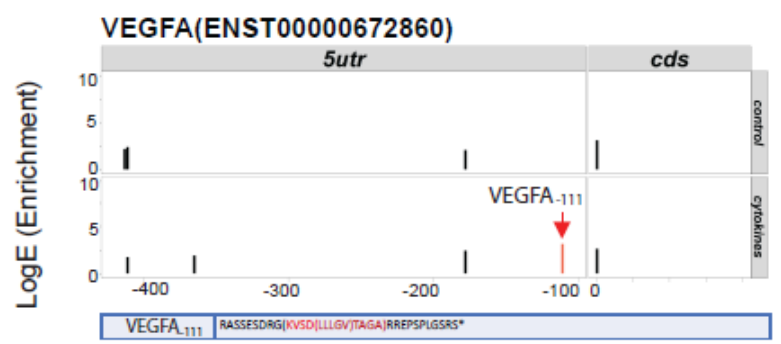

B.

PSMD8 (ENST00000215071)

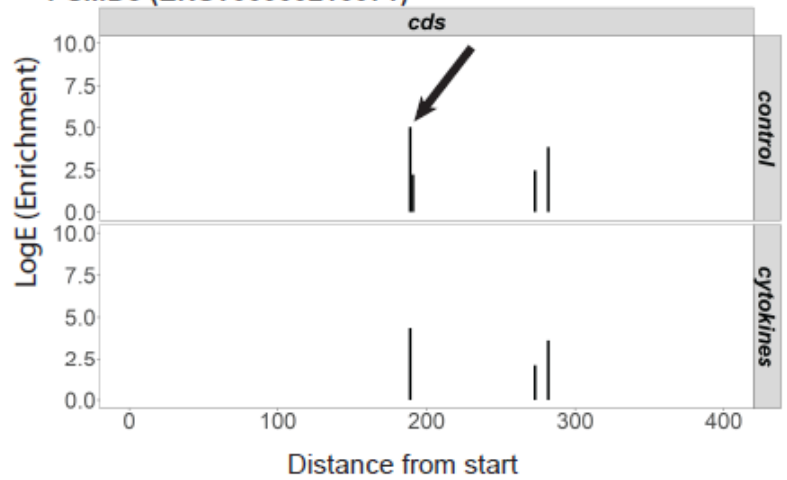

D.

PGRMC1 (ENST00000217971)

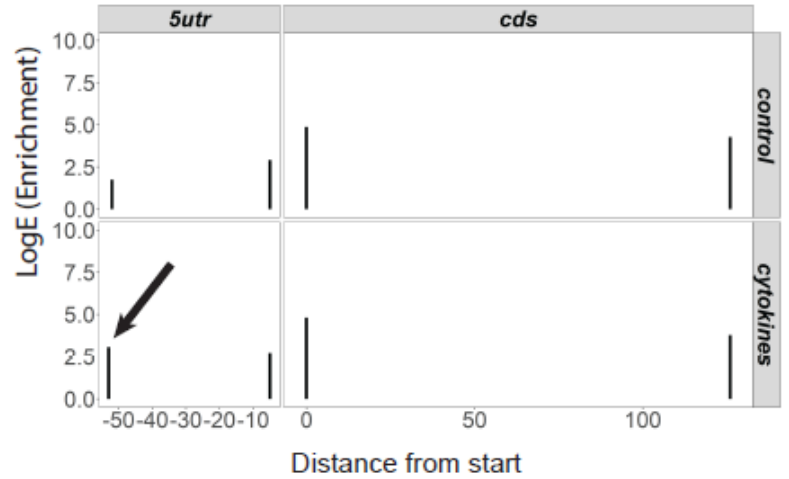

F.

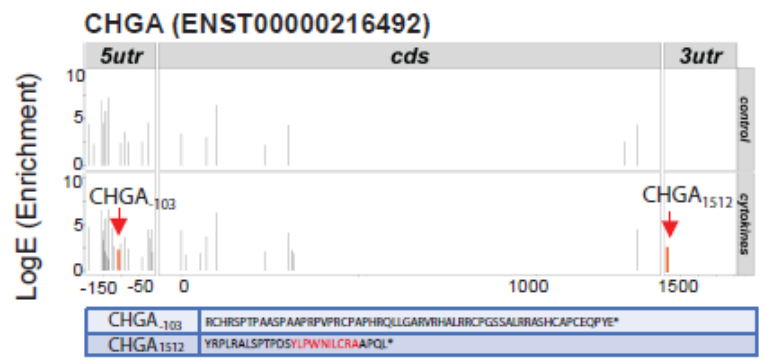


Supplementary Figure S5

A.

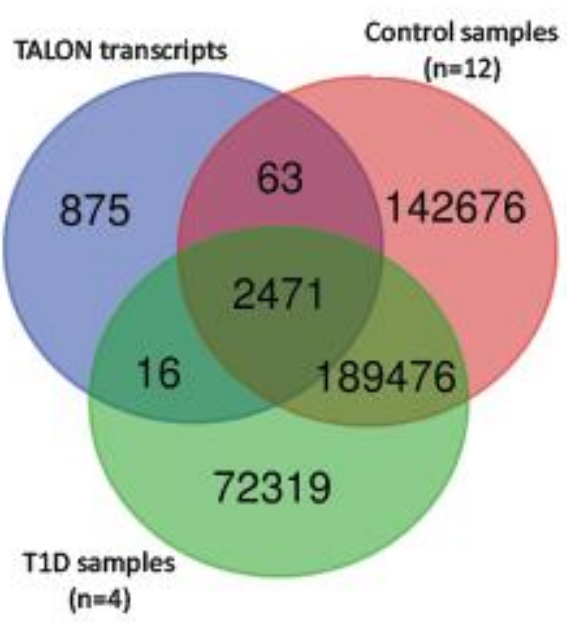

c.
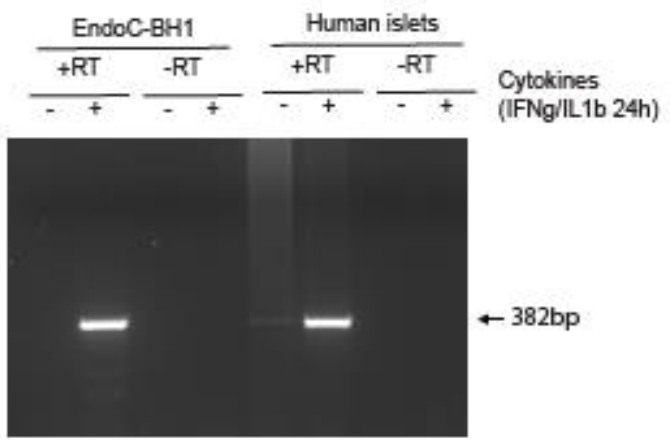

PSMB9 (TALONT000709680)

E.
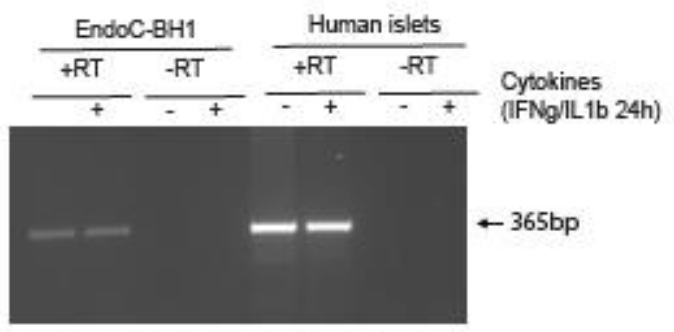

INS-IGF2 (TALONT000499153)
B.

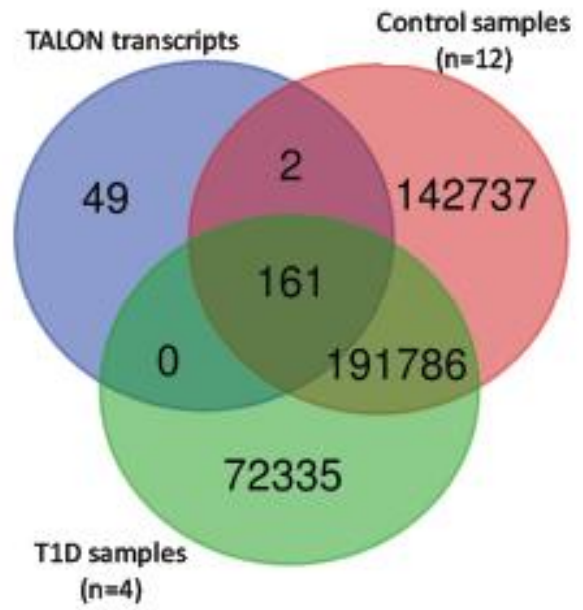

D.

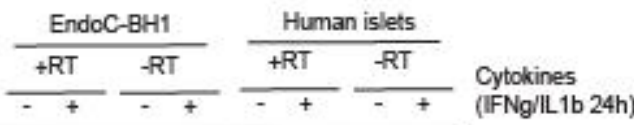

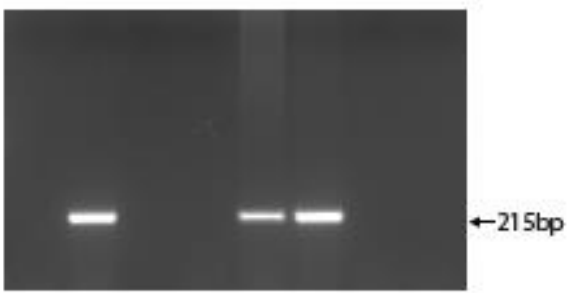

HLA-C (TALONT000700063)

F.

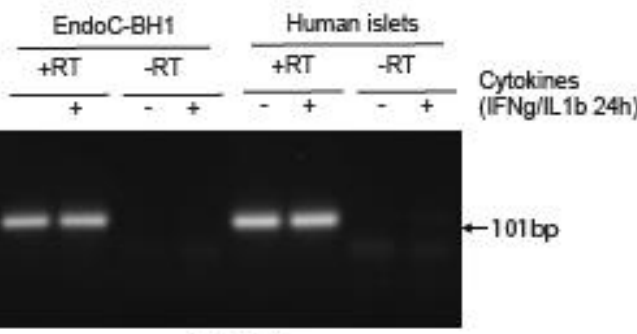

GAPDH 
Figure S6.

A.

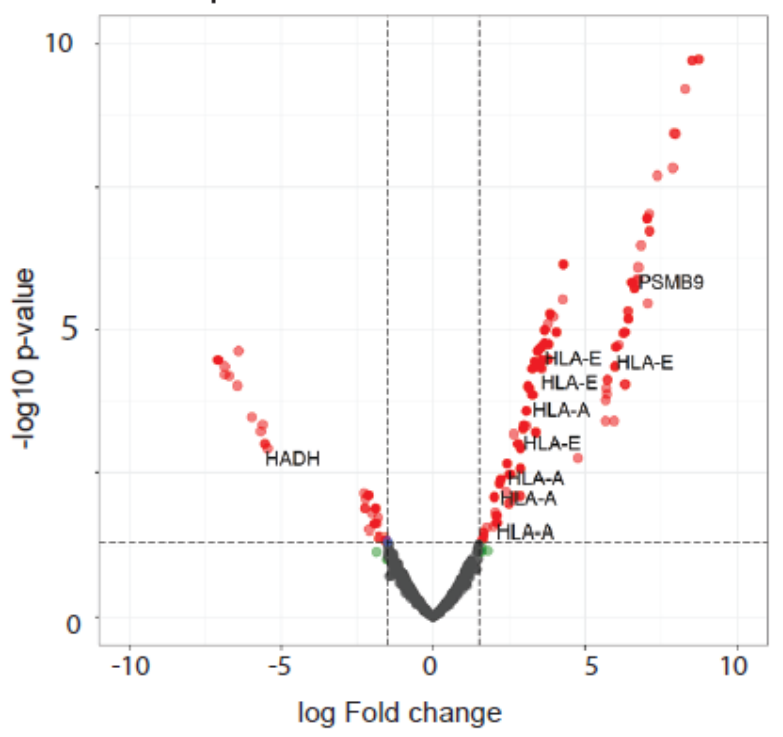

B.

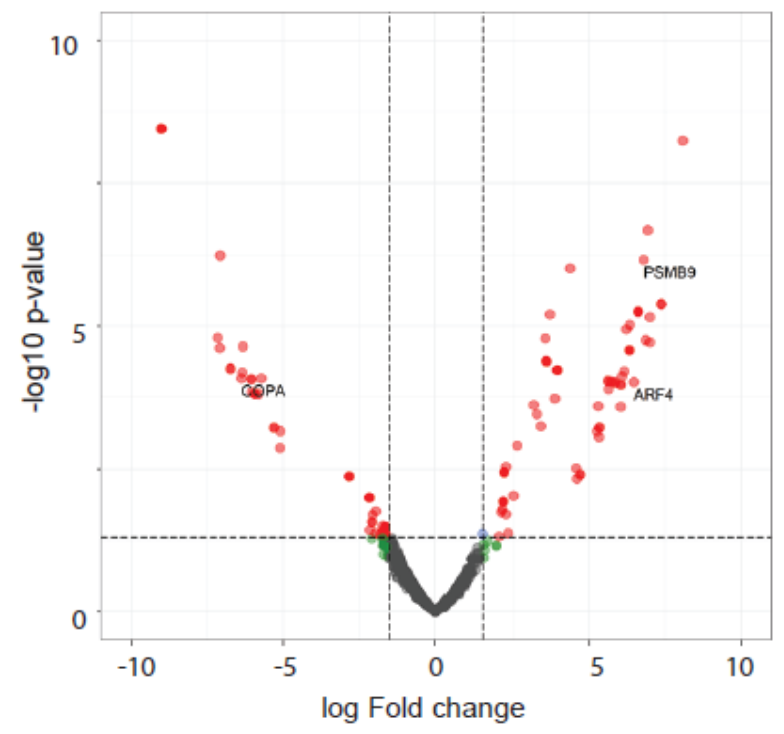


Figure S7.

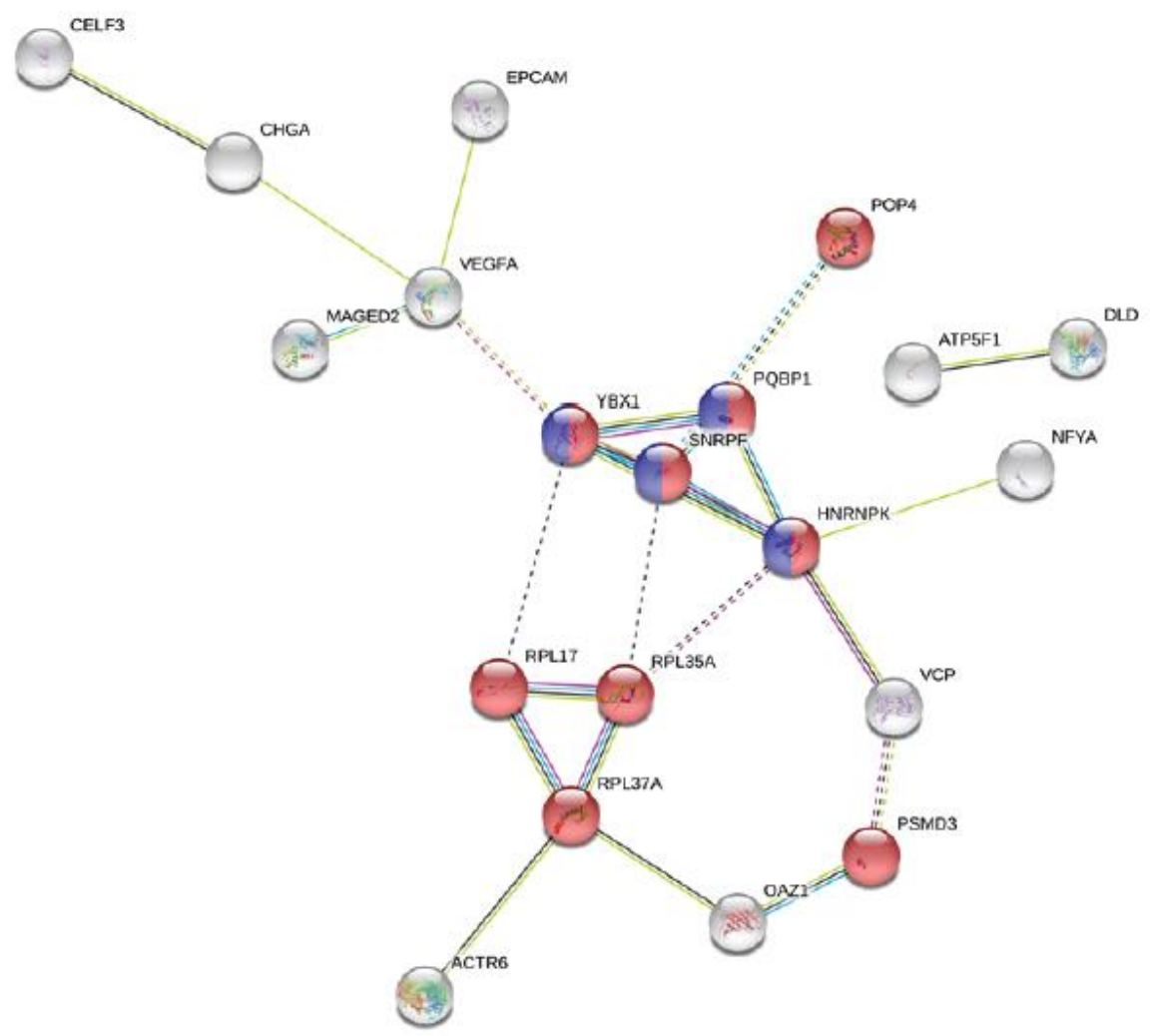




\section{Figure S8.}

A.

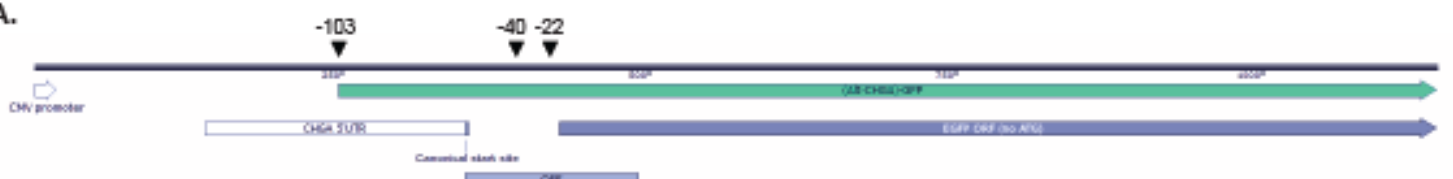

B.

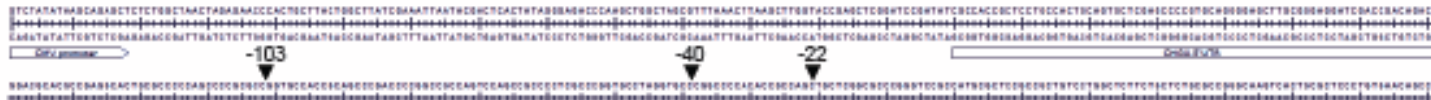

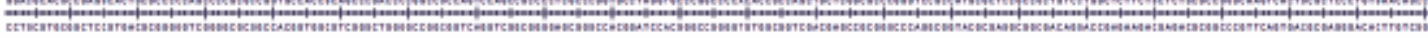

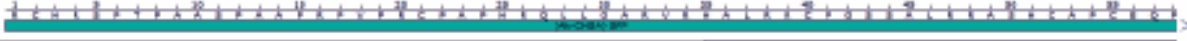

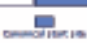

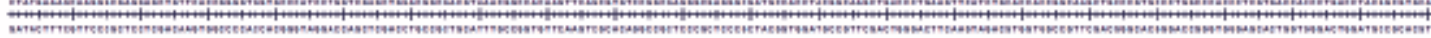

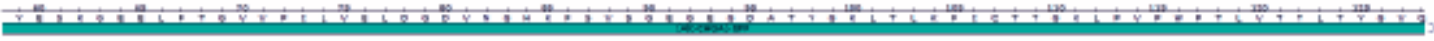

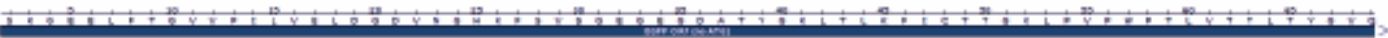
(2)

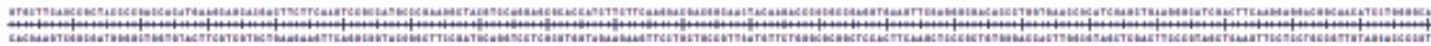
70

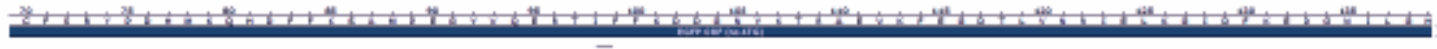

c.

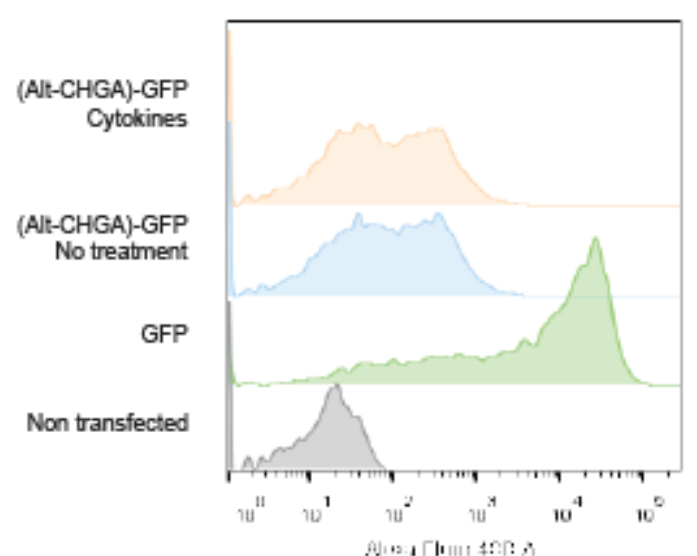

A.
D.

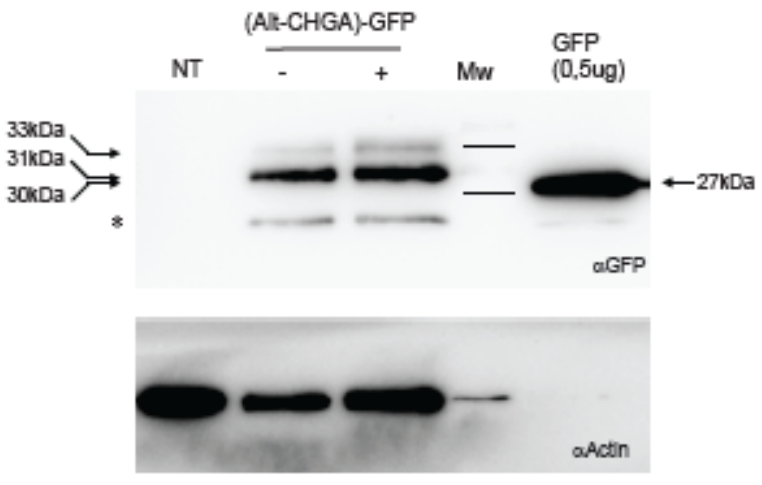

